\title{
Los lechos nocturnos en los hogares de Pedro Tomé González (Burgos, 1703-1782)
}

The night beds in homes by Pedro Tomé González (Burgos, 1703-1782)

Francisco Sanz de la Higuera

IES Torreblanca (Sevilla)

CESXVIII, núm. 28 (2018), págs. 281-310 DOI: https://doi.org/10.17811/cesxviii.28.2018.281-310

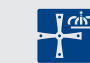




\section{RESUMEN}

Los lechos nocturnos en los que yacieron, en el devenir del siglo XvIII, Pedro Tomé González y los integrantes de su hogar conforman un parámetro diagnóstico de análisis. ¿Cómo fueron perfilando, entre nupcias y óbitos, la búsqueda de un mayor confort doméstico, de un sesgo exquisito de más modernidad, paralelo a la consecución de una buena situación socioeconómica y financiera? Desde sus humildes orígenes como tendero hasta los momentos más exultantes, en su calidad de empresario lanero y administrador general de la Santa Cruzada en Burgos, Tomé mejoró significativamente sus niveles de renta y fortuna. Y, también, las calidades y la disposición de sus interiores domésticos, en especial en lo tocante a las cantidades y calidades de los mobiliarios, menajes y ornamentación de las camas que les acogían en la nocturnidad.

Palabras clave

Lechos nocturnos. Niveles de consumo. Tomé González. Burgos. Siglo XVIII.

\section{Abstract}

The nigth beds where Pedro Tomé González and the members of his household lay throughout the eighteenth century make up a diagnostic vortex to be analysed. How were these items, between nuptials and deaths, searching for greater domestic comfort, exquisite bias of more modernity, parallel to the achievement of a good socioeconomic and financial situation. From a humble beginning as a shopkeeper to the most exultant stints, as a wool businessman and general manager of the Holy Crusade in Burgos, Tomé significantly made his income and fortune levels greater. Consequently, the quality and disposition of his domestic interiors, especially with regard to the quantities and qualities of the furniture, decorations and ornamentation of the beds that welcomed them at night were highly improved.

KEY WoRDS

Night beds. Level of consumption. Tomé González. Burgos. Century XvIII.

Recibido: 28 de enero de 2018. Aceptado: 3 de marzo de 2018. 
... y es adverttenzia que así la manta como el Colchón eran Nuebos pero como son cossas que sino se Usan se destruyen están ya algo andados... ${ }^{1}$.

\section{Introducción, fuentes documentales y aproximación bibliográfica}

Los inventarios de bienes, en especial los post-mortem, nos acercan a los enseres y pertrechos de un hogar en un momento puntual de su existencia, merced a una «instantánea» sincrónica redactada por un escribano, notario de la disponibilidad de tales propiedades. El cómputo de sus contenidos — mobiliario, vestuario, menajes de cama, menajes de mesa y cocina, objetos de adorno personal o de la decoración domestica, relojes, carruajes, etcétera-, y las tasaciones de que son objeto, nos asoman, en la medida de lo posible, a la cuantificación de sus niveles de fortuna, a su cultura material ${ }^{2}$. A la postre, también es posible elucubrar sobre las características de sus peculiares culturas de las $\operatorname{apariencias}^{3}$ e, igualmente, efectuar una reconstrucción de la historia de las

1 Archivo Histórico Provincial de Burgos. Protocolos Notariales -AHPB. PN en lo sucesivo—. José Fernández Guilarte. Legajo 7004 (23 de febrero de 1734), f. 217v (206-234). Inventario de bienes (postmortem) de doña María Fausta de La Gasca, viuda de don Francisco de la Torre Argaiz.

2 De entre las muchas, y excepcionales, aportaciones sobre cultura material en la Edad Moderna descuellan, citadas sin un ánimo exhaustivo, Hortensio Sobrado CorReA, «Los inventarios post-mortem como fuente privilegiada para el estudio de la historia de la cultura mate en la Edad Moderna», Hispania, 215 (2003), págs. 825-862; Máximo García FernándEz, «La cultura material doméstica en la Castilla del Antiguo Régimen», en Máximo García Fernández y Ma Ángeles Sobaler Seco (coords.), Estudios en homenaje al profesor Teófanes Egido, vol. II, Gráficas Andrés Martín, Valladolid, 2004, págs. 249-270; Isabel dos Guimaraes SA y Máximo García Fernández (dirs.), Portas adentro. Comer, vestir, habitar (ss. XVI-XIX), Universidade de Coimbra y Universidad de Valladolid, Coimbra y Valladolid, 2010; Fernando Ramos Palencia, Pautas de consumo y mercado en Castilla, 1750-1850. Economía familiar en Palencia al final del Antiguo Régimen, Sílex, Madrid, 2010; Raffaela SARTI, Vida en familia. Casa, comida y vestido en la Europa Moderna, Crítica, Barcelona, 2002; Renata Ago, Il gusto delle cose, Donzelli Editore, Roma, 2006; Carole Shammas, The Preindustrial Consumer in England and America, Clarendon Press, Oxford, 1990 y Lorna Weatherill, Consumer Behavior and Material Culture in Britain, 1660-1760, Routledge, Nueva Cork y Londres, 1988.

3 Entre otras notables aportaciones, Antonio Álvarez-Ossorio Alvariño, «Rango y apariencia. El decoro y la quiebra de la distinción en Castilla (ss. XVI-XVIII)», Revista de Historia Moderna, 17 (19981999), págs. 263-278); Daniel Roche, La culture des apparences, une histoire du vêtement (XVIIe-XVIIIe), Fayard, París, 1989; Máximo García Fernández, «Percepciones de la apariencia castellana dentro de España y en Roma: imagen, cultura material y estilos de vida a finales del Antiguo Régimen», Cuadernos 
emociones $^{4}$, con las que convivían y que les albergaban. Empero, dichos inventarios delatan también algunas patologías de singular calado. Sobre todo en lo tocante a cómo evolucionaba su uso cotidiano y al contraste existente con respecto a los niveles de fortuna de otros hogares en otras categorías socioprofesionales. Las pertenencias se heredaban o se compraban, de primera o de segunda mano, en su uso se deterioraban o se perdían inexorablemente, las estrategias de consumo doméstica determinaban su desaparición y su eventual reposición por enseres de estreno... En otras palabras, "Con questo tipo de documentazione sappiamo cosa la gente aveva in casa, ma ignoriamo in che modo quegli oggetti siano stati acquisiti, quanto tempo siano rimasti in quella casa, quante trasformazioni abbiamo subito nel corso di quel periodo, como siano stati usati. Su tutto questo, gli inventari non hanno nulla da dire» ${ }^{5}$.

La cultura material es una de las formas esenciales de la historia social. De hecho, como argumenta Micheline Perrot — palabras con las que estoy substancialmente de acuerdo - la cama, y la alcoba, forman parte esencial de «la historia social de la vivienda [...] La habitación cristaliza las relaciones entre espacio y tiempo» y una «historia estética de los gustos y los colores, descifrada en la acumulación de objetos e imágenes, y los cambios de decoración, el paso del tiempo que les es consustancial $[\ldots]{ }^{6}$. «La habitación ha sido siempre un crisol de civilización, a la vez productora de normas, lugar para la creación y territorio para las experiencias» ${ }^{7}$. Existen múltiples transformaciones a que somete el devenir de la historia a las circunstancias colectivas y particulares. Los espacios comunes de antes van cediendo, de manera más sosegada o en un vertiginoso acontecer, según el caso, a una comparti-

Dieciochistas, 9 (2008), págs. 125-127; Alicia SÁNCHEz OrTíz, «El color: símbolo de poder y orden social. Apuntes para una historia de las apariencias en Europa», Espacio, Tiempo y Forma, Historia Moderna, 12 (1999), págs. 321-354 y Carlos Ladero Fernández, «La apariencia en tiempos de cónclave. Bienes del cardenal Solís en la Corte de Roma (1774-1775)», en Juan José Iglesias Rodríguez, Rafael M. Pérez GaRCía y Manuel F. Fernández Chaves (eds.), Comercio y cultura en la Edad Moderna, Universidad de Sevilla, Sevilla, 2015, págs. 1873-1886.

4 Descuellan las aportaciones de Juan Manuel Zaragoza Bernal, «Historia de las emociones: una corriente historiográfica en expansión», Asclepio, 65 (2013), págs. 1-10 y «Ampliar el marco. Hacia una historia material de las emociones», Vínculos de Historia, 4 (2015), págs. 28-40; Jan Plamper, «Historia de las emociones: caminos y retos», Cuadernos de Historia Contemporánea, 36 (2014), págs. 17-29; Barbara Rosenwein, «Problems and Methods in the History of Emotions», Passions in Context, 1 (2010), págs. 1-32 y Peter Stearns y Carol Stearns, «Emotionology: Clarifying the History of Emotions and emocional Standarts», The American Historical Review, 90 (1985), págs. 813-836. Significativas también las propuestas de Francesca Randazo Eiseman, «Los imaginarios sociales como herramienta», Imagonautas, 2 (2012), págs. 77-96.

5 Renata AGo, Il gusto delle cose, Introduzione, XIV.

6 Michelle Perrot, Historia de las alcobas, Situela, Madrid, 2011, pág. 18.

7 Michelle Perrót, Historia de las alcobas, pág. 446. 
mentación espacial. Ello se traduce, por fuerza, en un progresivo aislamiento, entre la naturalidad de la desnudez y la eclosión de la vergüenza, más o menos enfermiza ${ }^{8}$.

Es esta problemática una más de las que se detectan en las reconstrucciones históricas de la cultura material. La sincronía, en su verticalidad estática, no permite sospechar el devenir de la sincronía, de la horizontalidad dinámica del paso del tiempo, salvo que dispongamos de dos o más documentos de similar índole, entre nupcias y óbitos ${ }^{9}$, para un mismo hogar. ¿Es asequible solventar, en la medida de lo posible, tales carencias? Aunque no es aceptable por completo la realización de extrapolaciones de tendencias o de circunstancias entre unos hogares y otros o entre los componentes de una misma categoría socioprofesional o entre unas categorías socioprofesionales y otras. El hecho de disponer de varios inventarios, en sucesión temporal, para un mismo individuo da acceso a unas proyecciones que pueden generar modelos o paradigmas de contraste en la misma ciudad o con otras localidades, cercanas o lejanas.

No es habitual, lamentablemente, disponer para una misma persona de varios inventarios de bienes, ya fuera éstos motivados por la celebración de nupcias o con motivo de los fallecimientos de uno u otro cónyuge. Las circunstancias asociadas a la existencia del «empresario» ${ }^{10}$ don Pedro Tomé González ${ }^{11}$ posibilitan llevar a cabo un análisis en diacronía de su cultura material, de la cultura de las apariencias en la que estaban enclavados y de las peculiaridades que les acompañaban, y envolvían, en lo tocante al «[H]echo cottidiano». La trayectoria vital de Pedro Tomé se caracterizó por el éxito en los negocios, si bien también se detectan algunas tragedias —en especial la que rodeó la precipitada huida de su hijo primogénito, Juan Manuel, su lugarteniente y heredero del tinglado empresarial familiar-. En los momentos de felicidad, progenitor y descendiente instalaban en la misma vivienda, aunque en habitaciones separadas,

8 Norbert ELÍAS, «La cortesía del lecho. Transformaciones en el uso del dormitorio», Arquitectura y vivienda, 14 (1988), págs. 18-24.

9 Francisco Sanz de la Higuera, «Cultura material entre nupcias y óbitos en el Burgos del Setecientos», El Futuro del Pasado, 7 (2016), págs. 295-322.

10 Ángel García SAnZ, «Empresarios en la España del Antiguo Régimen: ganaderos trashumantes, exportadores de lana y fabricantes de paños», en Francisco Comín y Pablo MarTín Aceña (coords.), La empresa en la historia de España, Editorial Civitas, Madrid, 1996, págs. 93-113 y Joaquín Ocampo SuÁrez-Valdés, Empresa y empresarios en el siglo XVIII en el norte de España, Trea, Oviedo, 2012, págs. 9-38.

11 Francisco SANZ de LA Higuera, «Las restauraciones del Consulado de Burgos en el siglo XVIII», Historia, Instituciones, Documentos, 29 (2002), págs. 429-458, «Familia, hogar y vivienda en Burgos a mediados del siglo XVIII", Investigaciones Históricas, 22 (2002), págs. 165-211 y «Un esperpéntico asuntillo de Estado: la casa de los Tomé en el Setecientos burgalés», Cuadernos de Estudios del Siglo XVIII, 21 (2011), págs. 287-318. 
sus lechos nocturnos, generando un hogar múltiple ${ }^{12}$. La fulminante defección del citado Juan Manuel dejó en el vacío esa convivencia y produjo un amargo cataclismo de notoria trascendencia.

Su matrimonio con Isabel de Castro en $1703^{13}$, la defunción de la susodicha en $1724^{14}$ y sus segundas nupcias, en esta ocasión con doña Josefa Carrera en ese mismo año ${ }^{15}$, sus propios óbitos, el de él en $1764^{16}$ y el de ella en $1782^{17}$, generaron cuatro inventarios de bienes, de singular aprovechamiento para dar cuerpo a esta reconstrucción histórica ${ }^{18}$. Merced a sus apretados contenidos, tenemos acceso a los enseres y pertrechos que modelaban sus existencias. En este caso, en especial, al mobiliario, menajes y colgaduras que empaquetaban sus cuerpos en las noches burgalesas del XVIII. ¿Cómo evolucionaron los distintos lechos nocturnos? ¿De cuántos muebles - camas, catres, cujas y cunas — disponían en el interior de sus estancias? ¿QQué menajes nocturnos cubrían sus cuerpos? ${ }^{20}$ ¿Se embutían entre «Colgaduras» con cortinas para dar intimidad a la convivencia marital? Las puertas en general y las puertas y cortinas de las alcobas en particular creaban una doble dimensión, no necesariamente antagónica ni dramática, entre la realidad interior de la vivienda y la exterior a la calle —en una época en que aún lo privado y lo público se confundían con relativa facilidad_- llevada al extremo en lo referente a aquellos hogares en que se establecían unas fronteras tupidas entre lo interior del «Echo cottidiano» y lo social y colectivo del resto de las estancias de la vivienda.

12 Francisco García González, La Sierra de Alcaraz en el siglo XVIII. Población, familia y estructura agraria, Instituto de Estudios Albacetenses, Albacete, 1998, en especial el Cap. II de la Segunda parte, págs. 207-247 y la bibliografía, págs. 435-469.

13 Archivo Diocesano de Burgos (ADB), San Román, Matrimonios, 16 de octubre de 1702, f. 77r. Isabel de Castro había contraído nupcias previamente con Jerónimo Núñez. ADB, San Román, Matrimonios, 10 de febrero de 1700, f. 8 r.

14 La defunción de Isabel de Castro en Archivo Capitular de la Catedral de Burgos (ACCB), Santiago de la Capilla, Cuanta de funerales, 16 de febrero de 1724, f. 160-161.

15 ACCB, Santiago de la Capilla, Matrimonios, 25 de febrero de 1725, f. 342r.

16 ADB, San Martín y Viejarrúa, Defunciones, 4 de julio de 1764, ff. 305-306.

17 ADB, Viejarrúa, Defunciones, 3 de julio de 1781, f. 349r.

18 Archivo Histórico Provincial de Burgos (AHPB). Protocolos Notariales (PN). Inventario de bienes, por segundas nupcias, y carta de arras, entre Pedro Tomé e Isabel de Castro. Legajo 6917. José de Mata. 11 de enero de 1703, ff. 218-238. AHPB. PN. Inventario de bienes por óbito de Isabel de Castro. Legajo 6964. Martín de Robredo. 14 de enero de 1724, ff. 340-353. AHPB, Justicia Municipal. Inventario post-mortem de Pedro Tomé. Legajo 977. Juan Antonio Fernández Guilarte. 14 de julio de 1764, ff. 21-127 y Archivo Municipal de Burgos (AMB). Inventario post-mortem de Josefa Carrera. Legajo HI-5253. Francisco de Villafranca. 26 de febrero de 1782, ff. 1-71.

19 Francisco SAnz de la Higuera, «Pajas, catres, cujas, camas,... El lecho cotidiano en el Antiguo Régimen: Burgos (1740-1780)», Cuadernos de Investigación Histórica, 26 (2009), págs. 435-499.

20 Francisco SAnz de la Higuera, «Evolución de los lechos cotidianos y los menajes nocturnos en el XVIII burgalés», Cuadernos de Investigación Histórica, 28 (2011), págs. 389-431. 
El éxito socioeconómico que acompañó a Pedro y a Josefa Carrera a lo largo de sus existencias se reflejó también en cómo disponían los lechos nocturnos que poblaban los «Quartos» de sus viviendas, sobre todo la de la plaza del Sarmen$\mathrm{tal}^{21}$. No se trata, empero, de una reflexión positivista sobre los hogares de Pedro Tomé González sin más. Se efectúa en estas páginas un contraste intenso sobre cómo resolvían la problemática nocturna en los hogares de las demás categorías socioprofesionales de la ciudad en la que residían. No sólo la de los profesionales de las administraciones eclesiásticas en la que estaba implicado Tomé González ${ }^{22}$ sino con respecto a otras realidades laborales de los vecinos y hogares burgaleses. La tendencia hacia el enriquecimiento, y en concreto la experimentada por Tomé, augura una mejora notable en la disponibilidad de enseres y pertrechos a los que el hogar tenía acceso. Ello significa, en la práctica, la efectiva incorporación de menajes, objetos y aditamentos no sólo para el uso de las personas, y de su adorno personal, cuanto para el aclimatamiento del interior de las estancias de la vivienda. Fracasar y empobrecerse reducía, a veces de manera vertiginosa, la cantidad y calidad del patrimonio y de los objetos que edulcoraban sus existencias.

La diacronía en la existencia de Pedro Tomé es, también, la de los grupos intermedios, ni cortesanos ni privilegiados, que se afirmaron en el universo castellano, adquiriendo un protagonismo efectivo en los procesos de transformación social. La visualización, pública y privada, de sus culturas materiales, cotidianas o extraordinarias, está relacionada con prácticas rupturistas y modernizadoras, que cristalizaron, por imitación aristocrática o por mera aclimatación objetiva, en la posesión de ciertos enseres paradigmáticos ${ }^{23}$

La documentación recopilada en los protocolos notariales —inventarios de bienes, últimas voluntades, etcétera- se complementa, necesariamente, con los «memoriales» localizados en el Catastro elaborado a instancias del Marqués de la Ensenada ${ }^{24}$ y con el seguimiento del ciclo familiar de Pedro Tomé y Josefa Carrera en los sacramentales de las parroquias burgalesas custodiados en el Archivo Diocesano de Burgos.

Unas circunstancias aparentemente anecdóticas, los lechos nocturnos de un individuo residente en Burgos en el siglo XVIII, se pergeñan como una fórmula

21 Francisco Sanz de la Higuera, «Un esperpéntico asuntillo de Estado: La casa de los Tomé en el Setecientos burgalés», Cuadernos de Estudios del Siglo XVIII, 21 (2011), págs. 287-318.

22 Francisco Sanz de la Higuera, «Los mayordomos de la Mesa Capitular de la Catedral de Burgos en el Setecientos (1707-1782)», Trocadero, 25 (2013), págs. 117-146.

23 Máximo García Fernández, «Cambios y permanencias en la cultura material cotidiana no privilegiada: un mundo complejo. Castilla (y Portugal) a finales del Antiguo Régimen», Revista Histórica (Sao Paulo), 175 (2016), págs. 173-202.

24 Archivo de la Diputación Provincial de Burgos (ADPB). Catastro de Ensenada (CE). Respuestas Particulares (PR), Libros 344-349. 
metodológica y axiomática que va más allá del mero carácter micro-histórico para ser considerada como una herramienta didáctica y procedimental no sólo para un hogar en concreto sino para una ciudad en su conjunto. El «[H]echo cottidiano» se percibe como uno de los vórtices esenciales de la historia social, en la medida en que tal categoría abarca desde lo más recóndito, e íntimo, de los comportamientos familiares hasta lo más global y colectivo de la sociedad del Antiguo Régimen in extenso. Por lo general, en una cama se nace y se muere. En un lecho se suelen ejecutar los requerimientos imprescindibles para la reproducción humana - léase sexualidad — y se descansa tras la fatiga de los quehaceres profesionales o, paradójicamente, para prepararse para ellos. La dimensión social de la cama aglutina un tercio de la existencia del género humano, aunque sea en la intimidad somnífera del dormir nocturno.

Esta reconstrucción histórica se nutre, simultáneamente, con la documentación recopilada en los protocolos notariales, por una parte, y, por otra, con el acervo bibliográfico esencial para temáticas modernistas como la cultura material y de los interiores domésticos, la historia de la cama y de la alcoba, la historia del mueble o las biografías de personajes modélicos para el siglo XVIII ${ }^{25}$. El Burgos del Setecientos tiene mucho que envidiar al Madrid o al Cádiz del Setecientos, por poner dos ejemplos significativos. Empero, Pedro Tomé González se instituye, en la práctica, como un epígono fundamental de su tejido urbano en el Setecientos, a la altura de acaudalados e influyentes personajes como Gonzalo del Río o Francisco de la Infanta ${ }^{26}$.

\section{Número de lechos y menajes nocturnos en los hogares de Pedro Tomé González}

Los edificios en los que Pedro Tomé albergó su hogar entre 1703 y 1764, junto con sus cónyuges, desplegaban, en la medida de lo posible, varios lechos nocturnos. El número de corresidentes de cada momento, la disponibilidad de estancias, los niveles de renta y fortuna a que se tenia acceso y las estrategias de descanso e intimidad que se definían según el caso explican de qué manera

25 Carlos Martínez Shaw, «Un mercader gaditano del siglo xviII: Agustín Ramírez Ortuño», Archivo Hispalense, 196 (1981), págs. 29-41; Juan Hernández Franco, «Una familia de la «nueva clase» política del siglo XviII: Los Robles Vives», Cuadernos de Investigación Histórica, 11 (1989), págs. 131-152; Margarita Vilar Rodríguez, «Éxito y ocaso de una saga de negociantes catalanes en Galicia: La casa de comercio Francisco Ferrer y Albà (1750-1860)», Cuadernos de Estudios Gallegos, 119 (2006), págs. 305-335 y Manuel Moreno Alonso, Retrato de familia andaluza con Las Indias al fondo. El Memorial de El Pintado (16971780), Alfar, Sevilla, 2000.

26 Francisco SANZ De la Higuera, «Las «restauraciones» del Consulado de Burgos en el siglo XVIII», Historia, Instituciones, Documentos, 29 (2002), págs. 429-458. 
se emplazaban y vestían, en calidad y en cantidad, el número de camas, catres o cujas precisas para asegurar el reparador descanso en la vigilia o cualquier otro quehacer biológico.

Cada inventario post-mortem, o en su caso los de segundas nupcias, es, en términos prácticos, una fotografía fija, una instantánea sincrónica para un momento, el del fallecimiento, o el de la celebración de un matrimonio. Empero, su ensamblaje en un convoy diacrónico múltiple, a modo de un eje cronológico o de un diagrama de Ishikawa, nos acerca al devenir de las transformaciones, incrementos o menguas, ocurridas en un hogar a lo largo del tiempo. Desde la perspectiva de lo nocturno, la mejoría, o el empeoramiento, en el número de lechos y en la calidad y la cantidad de los menajes de cama y de las colgaduras nos enuncia una inflación, o una deflación, en los volúmenes del nivel de fortuna y, por tanto, en su ubicación taxonómica en la pirámide socioeconómica y socioprofesional de la localidad de residencia. Los lechos nocturnos se evidencian como uno de los vórtices esenciales en la catalogación de la idiosincrasia y personalidad de un hogar. La tendencia era, y es, en gran medida, instalar una cama y desplegar un menaje nocturno y usufructuarlo durante un tiempo prolongado, en la medida que la durabilidad de los materiales lo permitiera. A cada etapa le corresponde un lecho cronificado y casi perpetuado. Fuera por comodidad, costumbre o inercia, el mobiliario nocturno, y gran parte de los menajes que lo vestían, eran para toda la vida, salvo convulsiones muy puntuales y extraordinarias.

La presencia física, o emocional, de Pedro Tomé discurrió, a la postre, por su horizontalidad nocturna en tres lechos distintos, acompañados, en el resto del entramado habitacional de su hogar, por otras camas, ocupadas por el resto de los corresidentes. La evolución en el volumen de sus niveles de fortuna —GRÁFICo I - tiene en el devenir de lo adscrito al descanso nocturno — GRÁFICo IIuna simbólica emulación. Tanto más tienes, tanto mejor duermes o, al menos, reposas en la vigilia de la noche. Es la historia social del microcosmos de los interiores domésticos.

El número de lechos y las magnitudes del mobiliario, los menajes nocturnos y la ausencia o presencia de colgaduras, así como una evaluación aproximada del lecho cotidiano del matrimonio, van a ser enfatizadas en los siguientes párrafos. En la práctica, cada hogar, y en este caso los protagonizados por Pedro Tomé, se afanaban, en la medida de sus posibilidades, para aclimatar sus existencias al atrezzo cotidiano de sus interiores domésticos. El «gusto delle cose» se substantivaba, en especial, en la definición de ambientes o bien sociales, la mesa de comer, o bien más íntimos, los lechos nocturnos. En ellos se materializaban unas emociones, fruto de diversas estrategias de convivencia, que 
GRÁFICO I. NIVEL deFORTUNA: TOMÉ GLEZ. y BURGOS

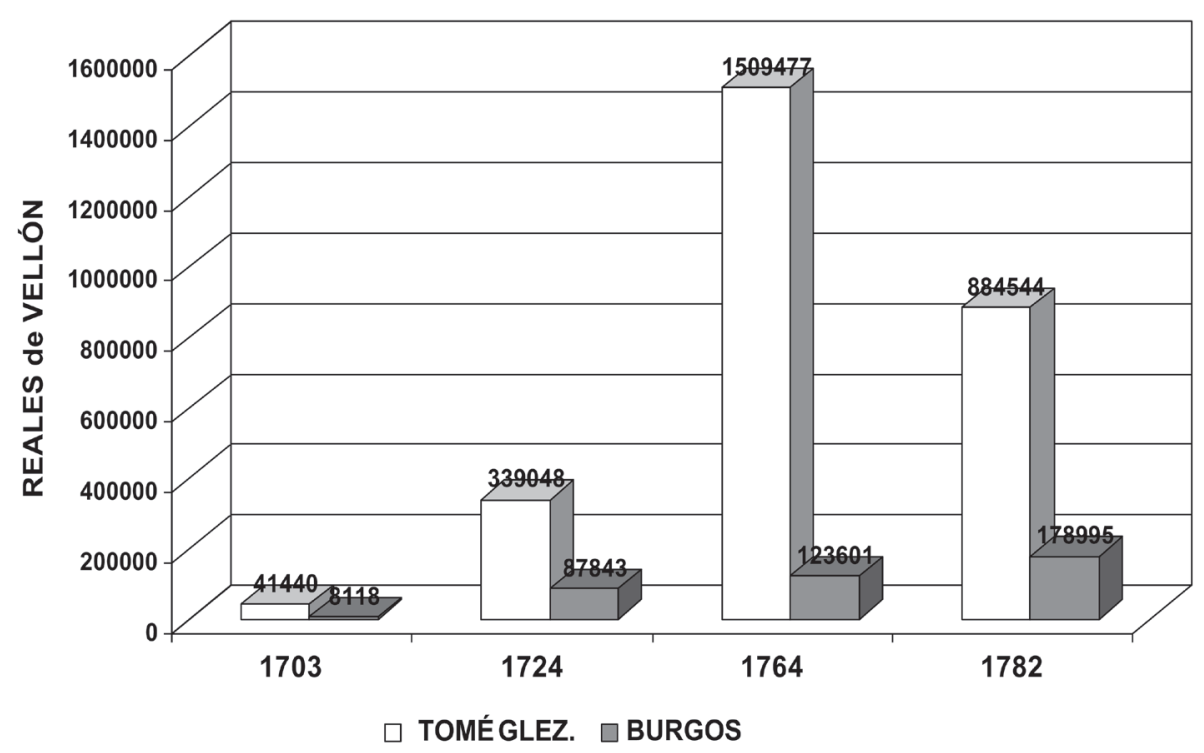

Elaboración propia. AHPB. PN. Múltiples Legajos.

GRÁFICO II. NÚMERO DE LECHOS NOCTURNOS DE TOMÉ GONZÁLEZ

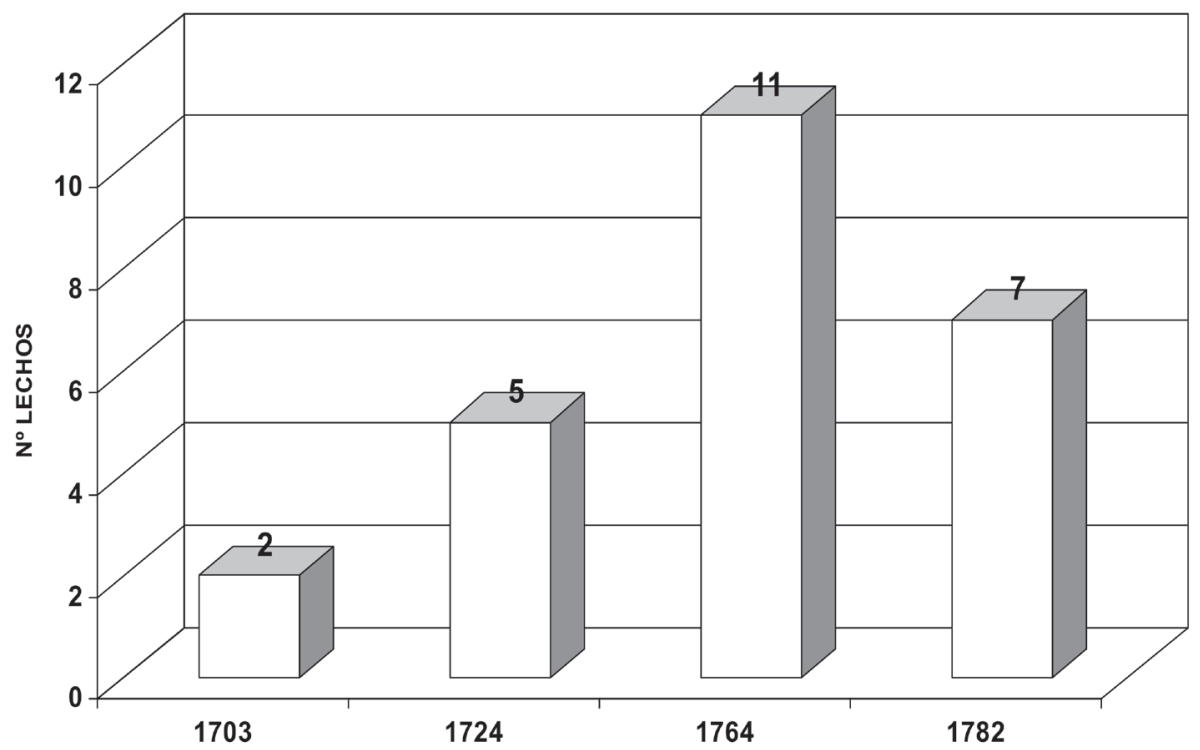

Elaboración propia. AHPB. PN. Múltiples Legajos. 
nos hablan de domicilios preñados de enseres y pertrechos cercanos, queridos, utilizados, funcionales.

En 1703, Pedro Tomé contraía matrimonio con Isabel de Castro. Ella era viuda y había «pasado a segundas numpzias y bodas con dho mi segundo marido abra como dos meses poco más o menos». Con Jerónimo Núñez, su primer cónyuge, estuvo casada «Ocho o nueve Messes poco más o menos, no Ybo ningunos Vienes gananciales que poder Poner por más asumentto deste Ynbenttario» ${ }^{27}$. De ese enlace nació María Núñez Castro, «de hedad de dos años y medio» en $1703^{23}$. Pedro Tomé era «mercader de Joyería» y «Solttero desde luego». Ella aportaba 21.440 reales de vellón y él, aproximadamente, 19.800 reales, es decir, un patrimonio conjunto de 41.240 reales $^{29}$.

En junio de 1706 - hasta enero de 1726 - , les encontramos instalados en la casa n. ${ }^{\circ} 139$ del elenco de edificios propiedad del Cabildo catedralicio, sita en la calle Cerrajería, inmueble por el pagaron 290 reales y 10 gallinas/año. Firmaron la escritura de arrendamiento por períodos de 6 años ${ }^{30}$. En el inventario de 1703, se indica que Doña Isabel estaba «deviendo de la rrenta de la Cassa que es propia del Cavildo de la dha Sta Yglesia a la Calle de la Zerrajería, y de rresto del año pasado de mil Settecienttos y Uno» 190 reales. Tal circunstancia evidencia que dicho inmueble había sido su hogar, y tienda, con el citado Gerónimo Núñez ${ }^{31}$.

En junio de 1708, contratan el alquiler de la casa n. ${ }^{\circ} 137$, propiedad también de la Mesa capitular, del Cabildo catedralicio, en la calle Cerrajería, por 3 años y 143 reales y 4 gallinas/año, inmueble demolido en $1725^{32}$.

En 1709, se efectúa el alquiler, vitalicio, de una casa en la Plaza Mayor, propiedad de la Condesa de Castrillo, «Por prezio y Rentta en cada Un año durante los largos días de su Existencia» y 700 reales/año ${ }^{33}$. En 1710, tomaron en arrendamiento una casa, propiedad de don Diego Luís de Arriaga, «a los Soportales de la polaina», por 9 años y 800 reales/año ${ }^{34}$. En 1712, Sebastián Salinas, mercader de joyería ${ }^{35}$, cede el arrendamiento de una casa, propiedad del Cabildo Catedral, en la calle de la Cerrajería, a Pedro Tomé e Isabel de Castro,

\footnotetext{
27 AHPB. PN. Legajo 6917. José de Mata. 11 de enero de 1703, f. 218r (218-229).

28 ADB. San Román. Bautizos. 10 de febrero de 1700, f. 8r.

29 AHPB. PN. Legajo 6917. José de Mata, 11 de febrero de 1703, ff. 218-229.

30 ACCB. Libro de cabezas de casa, 90, casa n. $^{\circ} 139$, f. 164.

31 AHPB. PN. Legajo 6917, f. 228r y ACCB. Libro de Redondo de la Mesa Capitular, 1702-1703.

32 ACCB. Libro de cabezas de casa, 90, f. 162 (1707-1712).

33 AHPB. PN. José Martínez Huidobro. Legajo 6843. 9 de octubre de 1709, ff. 691-698.

34 AHPB. PN. Domingo Ibáñez Varona, 6 de mayo de 1710, f. 278.

35 Francisco SANZ de la Higuera, «Aproximación a la locura en el Setecientos burgalés: cerebros, humores y economías en desequilibrio», Investigaciones Históricas, 29 (2009), págs. 41-68.
} 
edificio «en que anttes de aora los ottorganttes han Vivido y tenido tienda de Joyería (...) respecto de aber dejado la Vivienda de dha Casa y Trato de Joyería que en ella tenían y pasado a Vivir y havitar Otra suya y no nezesitar de la referida - están de acuerdo por no pagar de Vazio la Rentta de Zedersela y traspasársela à Pedro Thomé gonzález», por 9 años y 264 reales/año ${ }^{36}$.

En junio de 1718 - y hasta 1725-, accedieron también al alquiler de otro inmueble, en la Plaza del Sarmental, propiedad, igualmente, del Cabildo Catedral — casa n. ${ }^{\circ} 124-$, por la que abonaron 275 reales y 2 gallinas/año. La escritura de arrendamiento se firmó por 6 años ${ }^{37}$. Entre 1744 y 1762, fue ocupada por el medio racionero y músico de la Catedral don Antonio Diego ${ }^{38}$. En el inventario de 1724 se indica que ésta era la residencia de Pedro e Isabel en esos momentos —en «la Casa donde bibió y murió la dha $D^{a}$ Ysabel de Castro, que es la que havita el dho D. Pedro Thomé González, a la plazuela que llaman del Sarmental»—39.

La búsqueda de una vivienda, digna y asequible a sus negocios, responde a la articulación de unas estrategias residenciales que, desde las perspectivas profesionales, patrimoniales y conductuales, les asegurara óptimas perspectivas en la carrera por alcanzar un prestigio sólido y sostenible en la urbe castellana. La ciudad era un «teatro» en el que la elección de una residencia era un ingrediente fundamental en la jerarquización social y las señas de identidad de su hogar. La mejora en las condiciones de nocturnidad, materializadas en la calidad y la cantidad de sus lechos y menajes, está, también, estrechamente ligada a la incorporación a los parámetros esenciales del poder, de la autoridad y del reparto de privilegios ${ }^{40}$.

En la casa nupcial de Pedro e Isabel se desplegaron inicialmente 2 ó 3 lechos. En concreto, en primera instancia, «Una armadura de Cama de aya y Cabezera de los mismo con mástiles Altos y sus cordeles», tasada en 20 reales de vellón. Éste era, a mi juicio, el lecho matrimonial, arropado con los menajes habituales, hasta una suma aproximada de 301 reales. Además, se consignó en el inventario de bienes, en segundo término, «Una Armadura de Cama de aya de medios mástiles Sin Cabezera» (12 reales), probablemente lecho de la menor, María Núñez, sobre la que se desplegaron menajes por un valor cercano a los 217 reales. Los menajes descritos en el inventario posibilitan la existencia de

\footnotetext{
36 AHPB. PN. José de Mata. Legajo 6919/2, 20 de marzo de 1712, f. 627.

37 ACCB. Libro de cabezas de casa, 90, ff. 149-150.

38 ADPB. CE. RP, Libro 348, f. 37.

39 AHPB. PN. Martín Robredo. Legajo 6964, 14 de enero de 1724, f. 342v.

40 Georges Augustins, «Jerarquización social y señas de diferenciación: el caso de Évora en Portugal», Revista de Antropología Social, 12 (2003), págs. 121-142.
} 


\begin{tabular}{|c|c|c|c|c|c|c|c|}
\hline CUADRO I & \multicolumn{7}{|c|}{ Lechos nocturnos en los hogares de Pedro Tomé González } \\
\hline & & & & & Lecho & \\
\hline & No Lechos & Mobiliario (1) & Menajes (1) & Colgaduras (1) & Total & cotidiano (2) & $\%$ \\
\hline 1703 & 2 & 32 & 802 & 0 & 834 & 301 & 36.1 \\
\hline 1724 & 5 & 440 & 2779 & 1376 & 4595 & 1537 & 33.4 \\
\hline 1764 & 11 & 410 & 4951 & 1700 & 7061 & 2014 & 28.5 \\
\hline 1782 & 7 & 253 & 2940 & 1688 & 5588 & 2012 & 41.5 \\
\hline Promedio & 6 & 284 & 2868 & 1191 & 4519 & 1466 & 32.4 \\
\hline (1) Magnitudes en reales de vellón. & & & & \\
\hline (2) Lecho cotidiano del matrimonio - muebles, menajes y colgaduras -. & \\
\hline Elaboración propia.
\end{tabular}

otro lecho, aunque sin mueble, en el que quizá reposaba nocturnamente un criado o criada. En el inventario de 1703 se anotaron muebles nocturnos por un valor total de 32 reales, los menajes de cama ascendieron a 802 reales y no existían colgaduras en los lechos —CuAdro I- En total, 834 reales, un 15.1 $\%$ de su patrimonio ${ }^{41}$. Contrastado por el promedio de los cinco inventarios recopilados para 1703, tales cantidades son cercanas al sesgo de la ciudad en su conjunto, con una ligera relevancia para el hogar de Tomé, aunque sin estridencias —de promedio 3 lechos, 36 1/2 reales en el mobiliario, 496 1 1/2 reales en los menajes y 89 reales en las colgaduras_- El perfil de los tenderos Pedro Tomé e Isabel de Castro no disentía en mucho con el resto de sus convecinos en tales momentos - CuADRO II-.

En enero de 1724, al hilo del fallecimiento de Isabel de Castro, y para proteger los derechos, «persona y Vienes» de María Núñez, «su andrada», se elaboró el inventario post-mortem de las propiedades de ambos, sin «haver quedado por muerte de dha $d^{a}$ Ysabel de Castro y Castilla, su muxer, más Vienes, alajas, papeles y dinero que los que Van ynventtariados y ttasados» ${ }^{42}$. El cómputo, 339.048 1/2 reales de vellón, era una suculenta cantidad que evidenciaba, sin lugar a dudas, que el nivel de fortuna, y la comodidad en los interiores domésticos, en el hogar de Pedro Tomé había crecido como la espuma desde el momento del matrimonio. Pedro Tomé se comprometió a «Cuidar de la Persona de dha $D^{a}$ María Núñez» defender sus intereses, sus «Vienes y hazienda, así muebles como Rayzes, los quales Administtrará y arrendará y cobrará Sus fruttos y renttas, Caídas y que caieren, Y ttodo lo demás que a dha menor ttocare». Para ello «ttendrá libro de quentta y razón y la dará de ttodo lo que estubiere a su cargo y pagará el Alcanze o alcances que conttra él resulttaren, dando a dha menor bueno y sano

41 AHPB. PN. José de Mata. Legajo 6917, 11 de enero de 1703, ff. 224-226.

42 AHPB. PN. Martín Robredo. Legajo 6964, 14 de enero de 1724, f. 340r. 


\begin{tabular}{|c|c|c|c|c|c|c|c|c|c|}
\hline \multicolumn{7}{|c|}{ LECHOS NOCTURNOS EN LOS HOGARES DE PEDRO TOMÉ } \\
\hline
\end{tabular}

consejo» $»^{43}$. El pago de las deudas, lo perteneciente a la menor y la «Quentta y partizión», dejaron a Pedro Tomé con más o menos «mill Ducados de Vellón [...] los quales Confiesa Caven en la Dézima partte de sus Vienes, y casso que no quepan se los sittúa y señala en los demás que adelante tubiere y adquiriere», tal y como se explicita en las capitulaciones matrimoniales redactadas en su casamiento con doña Josefa Carrera, hija de Felipe Carrera ${ }^{4}$.

El inventario de 1724 nos muestra, en sus folios, que en la vivienda de Tomé se desplegaban, en sus estancias, 5 ó 6 lechos nocturnos, tasados en 440 reales. Sobre ellos se disponían menajes que sumaban 2.779 reales y, sí, 4 colgaduras que computaban, en total, 1.376 reales de vellón —Cuadro I- Desde los 834 reales de 1703 hasta los 4.595 reales de 1724, mucho había llovido y en la casa de Pedro Tomé los lechos nocturnos se había multiplicado por 5 1/2 el volumen del mobiliario y menajes nocturnos. Ahora sí se aprecia un incremento

43 AHPB. PN. Martín Robredo. Legajo 6964, 14 de enero de 1724, f. 340v.

44 AHPB. PN. Martín Robredo. Legajo 6965, 23 de febrero de 1725, f. 92-93. 


\begin{tabular}{|c|c|c|}
\hline \multirow[t]{2}{*}{ CUADRO III } & \multicolumn{2}{|c|}{ Lechos nocturnos de Pedro Tomé González } \\
\hline & 1703 & \\
\hline LECHO I: & LECHO II & LECHO III \\
\hline \multicolumn{3}{|l|}{ Lecho cotidiano MAT } \\
\hline 1 Cama 20 reales & 1 Cama 12 reales & \\
\hline 1 Colcha 55 reales & 1 Colcha 44 reales & 1 Colcha 33 reales \\
\hline 3 Sábanas 72 reales & 3 Sábanas 72 reales & 3 Sábanas 72 reales \\
\hline 2 Lenzuelos 30 reales & 1 Lenzuelo 15 reales & 1 Lenzuelo 15 reales \\
\hline 1 Colchón 36 reales & 1 Colchón 36 reales & 1 Colchón 36 reales \\
\hline 1 Pajero 10 reales & 1 Pajero 10 reales & 3 Almohadas 12 reales \\
\hline 3 Almohadas 12 reales & 3 Almohadas 12 reales & 1 Manta 16 reales \\
\hline 1 Cobertor 50 reales & 1 Manta 16 reales & \\
\hline \multicolumn{3}{|l|}{1 Manta 16 reales } \\
\hline \multirow[t]{2}{*}{ Total: 301 reales } & Total: 217 reales & Total: 184 reales \\
\hline & 1724 & \\
\hline LECHO I & LECHO II & LECHO III \\
\hline Lecho cotidiano MAT & 1 Cuja 10 reales & 1 Cuja 10 reales \\
\hline 1 Cama 400 reales & 1 Colgadura 400 reales & 1 Colgadura 240 reales \\
\hline 1 Colgadura 616 reales & 1 Colcha 120 reales & 1 Colcha 36 reales \\
\hline 1 Colcha 120 reales & 2 Lenzuelos 44 reales & 2 Lenzuelos 44 reales \\
\hline 2 Lenzuelos 44 reales & 2 Colchones 160 reales & 2 Colchones 140 reales \\
\hline 2 Colchones 160 reales & 2 Mantas 40 reales & 2 Mantas 40 reales \\
\hline 2 Mantas 40 reales & 1 Jergón 25 reales & 1 Jergón 25 reales \\
\hline 1 Jergón 25 reales & 4 Almohadas 12 reales & 4 Almohadas 12 reales \\
\hline 4 Almohadas 12 reales & 4 Sábanas 120 reales & 4 Sábanas 120 reales \\
\hline \multicolumn{3}{|l|}{4 Sábanas 120 reales } \\
\hline Total: 1537 reales & Total: 1021 reales & Total: 667 reales \\
\hline LECHO IV & LECHO V & LECHO VI \\
\hline 1 Cuja 10 reales & 1 Cuja 10 reales & 1 Colcha 36 reales \\
\hline 1 Colgadura 120 reales & 1 Colcha 36 reales & 1 Lenzuelo 22 \\
\hline 1 Colcha 36 reales & 2 Lenzuelos 44 reales & 2 Colchones 140 reales \\
\hline 2 Lenzuelos 44 reales & 2 Colchones 140 reales & 2 Mantas 40 reales \\
\hline 2 Colchones 140 reales & 2 Mantas 40 reales & 1 Jergón 25 reales \\
\hline 2 Mantas 40 reales & 1 Jergón 25 reales & 4 Almohadas 12 reales \\
\hline 1 Jergón 25 reales & 4 Almohadas 12 reales & 4 Sábanas 120 reales \\
\hline 4 Almohadas 12 reales & 4 Sábanas 120 reales & \\
\hline \multicolumn{3}{|l|}{4 Sábanas 120 reales } \\
\hline Total: 547 reales & Total: 427 reales & Total: 395 reales \\
\hline \multicolumn{3}{|c|}{ Fuente Documental: AHPB. PN. Legajo 6917 (1703), folios 218-229 } \\
\hline \multicolumn{3}{|c|}{ AHPB. PN. Legajo 6964 (1724), folios 340-353. } \\
\hline Elaboración propia. & & \\
\hline
\end{tabular}

substancial en las disponibilidades nocturnas. Tomando como referencia los promedios de Burgos en 1724, el número de lechos eran prácticamente similar pero ni los muebles implicados — 185 reales_, ni los menajes desplegados — 1.194 1/2 reales— ni las colgaduras — 500 reales— están a la altura de lo hallado en el hogar de Pedro Tomé e Isabel de Castro — Cuadro II—.

Una reconstrucción aproximada del lecho principal eleva su montante hasta los 1.537 reales. Estado dotado con «Una Armadura de Cama de nogal bronzeada la Cavezera con sus mástiles», tasada en 400 reales, y «Una Colgadura 
de Brocattel azul y dorado con su franja de seda que tiene Cientto y Cinquentta y quatro baras a quattro Reales vara en que enttra la Guarnizion» (616 reales). A continuación se suceden «Quatro Cujas de pino con sus Cordeles», de 10 reales cada una, sobre las que los componentes del hogar habían dispuesto camas de diferente cuantificación. En última instancia aparece un lecho sin mueble con menajes por un valor cercano a los 395 reales - CUADRO III- ${ }^{45}$.

Los 154.000 reales que en febrero de 1725 reunían Pedro Tomé (11.000 reales) y Josefa Carrera (44.000 reales), fueron el punto de partida de su segundo y último matrimonio. Al fallecer en 1764, de su inventario post-mortem se desprende que su nivel de fortuna era prácticamente 10 superior (1.509.477 reales), cantidad en la que los inmuebles reunidos (192.657 reales), el dinero en efectivo acumulado en casa (48.171 reales) pero, sobre todo, lo tocante al ganado merino trashumante (340.871 reales) y la lana disponible $(137.405$ 1/2 reales) ${ }^{46}$. El humilde tendero se había transformado en un rutilante «empresario» lanero y un notable gestor de responsabilidades tan importantes como la mayordomía de la Mesa Capitular de la Catedral, la administración general de la Santa Cruzada o del papel sellado, entre otros quehaceres ${ }^{47}$.

En 1725, Pedro Tomé y Josefa Carrera se hicieron con el alquiler de varios inmuebles. En primera instancia, la casa $n .^{\circ} 123$ propiedad del Cabildo catedralicio, edificio pegado a la muralla y sito en la Plazuela del Sarmental. Esta casa, construida de nueva fábrica en 1722-1723, se convirtió, desde el $1^{\circ}$ de enero de 1725, en el hogar de los Tomé-Carrera, hasta 1778, por 600 reales y 15 gallinas/año, con escrituras de arrendamiento de 9 años ${ }^{43}$. En segundo término, la casa n. ${ }^{\circ} 123$ bis, de igual propietario y ubicación, por 9 años y 300 reales y 5 gallinas/año. Fue demolida en 1762, para reedificarla y generar un sonado pleito entre los ocupantes y el dueño de los inmuebles ${ }^{49}$. En enero de 1725, también tomaron en alquiler la casa n..$^{\circ} 137$ del cabildo, sita en la calle Coronería, por 3 años y 228 reales y 4 gallinas/año, probablemente como depósito para sus mercaderías de paños y sedas y la gestión de las pilas de

45 AHPB. PN. Martín Robredo. Legajo 6964, 14 de enero de 1724, ff. 340-351.

46 AHPB. JM. Juan Antonio Fernández Guilarte. Legajo 977, 14 de julio de 1764, ff. 21-127.

47 Francisco SAnZ de la Higuera, «La cultura material de los tesoreros generales de la Santa Cruzada en el Burgos del siglo XVIII», Cuadernos de Estudios del Siglo XVIII, 25 (1025), págs. 317-336 y «Pólvoras, municiones, lanas, granos, bulas y papel sellado (1704-1764): Don Pedro Tomé González y la hora Navarra en el Burgos del siglo XvIII, Boletín de la Institución Fernán González, 227 (2003), págs. 375-411.

48 ACCB. Libro de cabezas de casas, 90, ff. 146-148 y ACCB. Libros de Redondo (1725-1782). En enero de 1782 dicha casas fueron tomadas en alquiler por su hijo don Antonio Tomé, regidor perpetuo del Concejo burgalés, por 9 años y 2.155 reales más 15 gallinas/año.

49 Francisco Sanz de la Higuera, «Un esperpéntico asuntillo de Estado...», Cuadernos de Estudios del Siglo XVIII, 21 (2011), págs. 287-318. 
lana, suyas o adquiridas en el Hospital del Rey y las actividades propias de la administración de la Santa Cruzada ${ }^{50}$.

En 1751, en el momento de la elaboración del Catastro de Ensenada, seguían ocupando ambas casas n. ${ }^{\circ} 123$, por las que abonaban al Cabildo Catedral, en total, 960 reales/año. El primer inmueble, con un alquiler anual de 645 reales, tenía dos habitaciones o plantas hábiles para la residencia, con 9.54 metros de altura. Cada planta, de 31.54 metros de largo y 12.86 metros de ancho, posibilitaba un espacio total para la corresidencia de, aproximadamente, 811.2 $\mathrm{m}^{2}$. Al ábrego lindaba con la Plazuela del Sarmental. Al cierzo con el jardín de la casa habitada por don Diego de Castro. Al regañón, con la casa siguiente, la 123 bis, y al solano con la muralla. En efecto, el inmueble adjunto suponía 315 reales/año de alquiler, tenía igualmente dos habitaciones o plantas y la misma altura. Era de fondo similar a la anterior, con 31.54 metros de largo, pero bastante más estrecha, con 4.56 metros de ancho. Aportaba, a la postre, otros $287.6 \mathrm{~m}^{2}$ de espacio para la convivencia cotidiana. Limitaba al ábrego con la Plazuela del Sarmental, al cierzo con el citado jardín, al regañón con la casa del susodicho don Antonio de Castro y al solano con la vivienda de don Santiago Núñez Monedero. En suma, las casas del Sarmental, en las que albergaba el hogar de los Tomé, suponían, sin contar con los entresuelos ni los desvanes, casi $1.100 \mathrm{~m}^{2}$ - únicamente 24 hogares superaban en superficie habitable la situada bajo titularidad de Pedro Tomé — ${ }^{51}$.

En la calle Avellanos, Pedro Tomé disponía en propiedad de una sólida mansión, de 9.9 metros de alta, con dos plantas útiles para la convivencia y aproximadamente $500 \mathrm{~m}^{2}$ de espacio habitable ${ }^{52}$. En 1736 estaba ocupada por don José Cazorla, administrador general de la renta de aguardientes y licores de Burgos, quien, con un contrata de arrendamiento de 2 años, pagaba 750 reales/ año ${ }^{53}$. En 1737, albergaba su hogar don Manuel Bermúdez, por 3 años (17371740) y 600 reales/año ${ }^{54}$. En 1747 los ocupantes eran, simultáneamente, el ci-

50 ACCB. Libro de cabeza de casas, 90, f. 160.

51 ADPB. CE. PR. Libro 347, ff. 92-96 (28 de junio de 1751). Francisco SAnz dE LA Higuera, «Familia, hogar y vivienda en Burgos a mediados del siglo XVIII: Entre cuatro paredes, compartiendo armarios, camas, mesas y manteles», Investigaciones Históricas, 22 (2002), págs. 165-212 y «La vivienda en el Burgos del Setecientos. Inflación en los alquileres, escasez en los bolsillos», en Margarita Birriel SAlcEdo (ed.), La(s) casa(s) en la Edad Moderna, Institución «Fernando el Católico», Excma. Diputación de Zaragoza, 2017, Zaragoza, págs. 429-469.

52 La «Casa principal sita a la Calle de los Abellanos de esta ciudad» a que nos referimos fue adquirida en 1734 - era propiedad anteriormente del convento de Santa Ana de San Sebastián y de la Capellanía de la ermita de San Miguel de Legazpia, fundada por don Domingo de Aguirre- AHPB. PN. Juan Antonio Fernández Guilarte. Legajo 7004, 1734, ff. 639-640.

53 AHPB. PN. Juan Antonio Fernández Guilarte. Legajo 7005, 28 de enero de 1736, f. 75.

54 AHPB. PN. Juan Antonio Fernández Guilarte. Legajo 7006, 29 de abril de 1737, f. 267. 
tado don Antonio Bermúdez — que se adjudicó los cuartos principales por 495 reales- y Manuel Bárcena, alojado en la segunda planta por 275 reales/año. La escritura de arrendamiento les concedía licencia de habitación por 4 años (1747-1750)5 ${ }^{55}$. En 1749, el arrendador era don Pedro Martínez de Armendariz, quien había firmado 9 años de alquiler (1749-1758) por 770 reales/año ${ }^{56}$. Como ocurría en otras ocasiones a lo largo y ancho de la ciudad, algunos propietarios preferían dar en alquiler sus inmuebles y residir en lugares más prominentes de Burgos, como, por ejemplo, la céntrica Plazuela del Sarmental, al lado de la Catedral, donde se codeaban con hogares de gran raigambre y peso socioeconómico y socioprofesional.

El hogar conformado por Pedro Tomé y Josefa Carrera era, en terminología de la Escuela de Cambridge, un (5b)8, es decir, un hogar múltiple con dos núcleos familiares, uno principal y otro descendente ${ }^{57}$. En primera instancia, los citados Pedro y Josefa, acompañados, en este momento, por su hijo Fernando, que «se le va aplicando a las Dependenzias De mi Casa», de 17 años (88), y tres criadas de servicio. Estaban ausentes, en 1751, Pedro Celestino, de 22 años, «que se Halla en la Corte romana, en donde le Mantengo para sus prettensiones $»^{58}$, y Antonio, estudiante de leyes, de 19 años, «al que mantengo en la ziudad de Balladolid para sus Cursos». El segundo núcleo familiar estaba integrado por su hijo primogénito, Juan Manuel, de 23 años, y su cónyuge, María Francisca de Lizárraga Ortíz Zárate, de 17 años, matrimonio sin descendencia a mediados de 1751, «quienes están en mi Casa y compañía». El servicio doméstico se completaba con un cochero, con residencia independiente y tres oficiales para el trabajo en el lavadero de lanas ${ }^{59}$.

El maravilloso inventario post-mortem elaborado al hilo del fallecimiento de don Pedro Tomé (1764) tiene la excelente particularidad de que el escribano detalló, de manera pormenorizada, las estancias de las viviendas citadas, de forma que es posible, aunque con cierta prevención, señalar cuáles eran las ubicaciones de los lechos en que se acogían nocturnamente sus componentes ${ }^{60}$. Ello

55 AHPB. PN. Juan Antonio Fernández Guilarte. Legajo 7015, 16 de enero de 1747, f. 43.

56 AHPB. PN. Juan Antonio Fernández Guilarte. Legajo 7015, 31 de mayo de 1749, f. 249.

57 Entre otras muchas posibilidades, Peter LASLETT, Household and family in past time, Cambridge, 1972; Francisco García GonzÁlez, La Sierra de Alcaraz..., págs. 207-248 y Rafael Torres SánchEz, «Estructura familiar y grupo doméstico en la España del s. XvıII», Cuadernos de Investigación Histórica, 13 (1990), págs. 189-215.

58 ADPB. CE. PR, Libro 347, ff. 92-96. Francisco SANZ DE LA Higuera, «Carrera eclesiástica y algunos deslices de Felipe del Hoyo y Pedro Celestino Tomé, arcedianos de Burgos (1731-1784)», Hispania Sacra, 124 (2009), págs. 649-690.

59 ADPB. CE. RP, Libro 347, ff. 92-96.

${ }^{60}$ Ténganse en cuenta las consideraciones de Hortensio SoBrado CorREA, «Los inventarios post-mortem ...», Hispania, 215 (2003), págs. 831-832 y las reflexiones, a tal efecto, de, por ejemplo, Natalia GonzÁLEZ 
nos permite sondear, con exquisito detalle, las estrategias ocupacionales y los grados de habitabilidad, domesticidad y sociabilidad de los hogares de Tomé, desde las ópticas de sus idiosincrasias socio-profesionales y socio-económicas ${ }^{61}$.

En la primera vivienda, se significan varias estancias para la convivencia y la intimidad, según el caso —Cuadro IV/1—. En el «Quartto Primero Prinzi$p a l »$, estaba habilitado el lecho del matrimonio titular, dotado con una cama de 150 reales, una colgadura de 1.000 reales y menajes nocturnos múltiples, hasta alcanzar, en total, una poderosa suma, 2.014 reales. En esa misma estancia, aparece otro lecho, con un catre de 30 reales y una colgadura de 100 reales, probablemente utilizada por Fernando. Este lecho acumulaba 438 reales, más o menos. En el «Quartto Terzero de Escusa», un catre de 40 reales, con menajes nocturnos desplegados para su vestimenta, que sumaban 372 reales. Cabe adjudicárselo, a mi juicio, a la pareja recién casada. En esa misma habitación nos topamos con otros dos lechos. Uno dotado con un catre de 40 reales y otro con un catre de 10 reales — quizá vacíos por la ausencia de Pedro Celestino y Antonio-. En un «Quarto Contiguo» se dispuso una cuja de 12 reales, probablemente ocupada por una de las criadas. En el «Quartto de las criadas» — ¿segundo piso? - había dos lechos. Uno con una cama de 30 reales y otro con una cuja de 8 reales ${ }^{62}$.

En la segunda vivienda, a la sazón destinada a quehaceres profesionales, dos de las estancias tenían lechos. El «Quartto Prinzipal de la Contaduría», dotado con una cuja de 8 reales, y el «Quartto Segundo de la Contaduría», en el que desplegaban dos lechos. Uno con una cama de 120 reales, otro con un catre de 30 reales —CuAdro IV/2—63.

Con el óbito de doña Josefa (1782) accedemos a otro prodigioso inventario post-mortem, excelente y guiado por el escribano con la exquisitez de las estancias dibujadas con esmero —Cuadro I- En el «Quartto Prinzipal», el lecho

Heras, «Casas de Madrid: vivir en La Corte en el siglo XVIII», en Margarita Birriel SAlCedo (ed.), La(s) casa(s) en la Edad Moderna, págs. 269-270.

61 Son de imprescindible consulta, lectura y reflexión, entre otras muchas opciones, Gloria Franco Rubio, «La vivienda en el Antiguo Régimen: de espacio habitable a espacio social», Chronica Nova, 35 (2009), págs. 63-103, «La vivienda en la España ilustrada: habitabilidad, domesticidad y sociabilidad», en Ofelia REY Castelao y Roberto López (eds.), El mundo urbano en el siglo de la Ilustración, Xunta de Galicia, Santiago de Compostela, 2009, págs. 125-135 y «El nacimiento de la domesticidad burguesa en el Antiguo Régimen. Notas para su estudio», Revista de Historia Moderna, 30 (2012), págs. 17-31; Richard Lick, «Les intérieurs domestiques dans la seconde moitié du xvпIe siècle d'après les inventaires après décès de Coutances», Annales de Normandie, 20 (1970), págs. 293-316 y Fabio DeI, «Oggetti domestici e stili familiari. Una recerca sulla cultura materiales tra famiglie toscane di classe media», Etnografía e recerca cualitativa, 2 (2009), págs. 279-293. Gloria Franco Rubio, El ámbito doméstico en el antiguo régimen. De puertas adentro, Madrid, Síntesis, 2018.

62 AHPB. JM. Juan Antonio Fernández Guilarte. Legajo 977, 14 de julio de 1764, ff. 21-127.

63 AHPB. JM. Juan Antonio Fernández Guilarte. Legajo 977, 14 de julio de 1764, ff. 21-127. 


\begin{tabular}{|c|c|c|}
\hline CUADRO IV/1 & \multicolumn{2}{|c|}{ Lechos nocturnos de Pedro Tomé González } \\
\hline & 1764 & \\
\hline & Primera vivienda & \\
\hline LECHO I: & LECHO II & LECHO III \\
\hline Cuarto $1^{\circ}$ Principal & Cuarto $1^{\circ}$ Principal & Cuarto $3^{\circ}$ Escusa \\
\hline \multicolumn{3}{|l|}{ Lecho cotidiano MAT } \\
\hline 1 Cama 150 reales & 1 Catre 30 reales & 1 Catre 40 reales \\
\hline 1 Colgadura 1.000 reales & 1 Colgadura 100 reales & 1 Colchón 50 reales \\
\hline 1 Colcha 350 reales & 1 Colcha 60 reales & 1 Cubre-Colchón 30 reales \\
\hline 3 Sábanas 132 reales & 3 Sábanas 108 reales & 1 Colcha 60 reales \\
\hline 2 Colchones 140 reales & 1 Colchón 50 reales & 3 Sábanas 90 reales \\
\hline 2 Cubre-Colchones 60 reales & 1 Cubre-Colchón 30 reales & 4 Almohadas 32 reales \\
\hline 4 Almohadas 48 reales & 4 Almohadas 24 reales & 1 Cobertor 40 reales \\
\hline 1 Cubre-almohadas 20 reales & 1 Manta 30 reales & 1 Manta 30 reales \\
\hline 1 Manta 90 reales & 1 Funda 6 reales & \\
\hline \multicolumn{3}{|l|}{4 Fundas 24 reales } \\
\hline Total: 2.014 reales & Total: 438 reales & Total: 372 reales \\
\hline LECHO IV & LECHO V & LECHO VI \\
\hline Cuarto $3^{\circ}$ Escusa & Cuarto $3^{\circ}$ Escusa & Cuarto Contiguo \\
\hline 1 Catre 40 reales & 1 Catre 10 reales & 1 Cuja 12 reales \\
\hline 1 Colchón 50 reales & 1 Colchón 50 reales & 1 Colchón 50 reales \\
\hline 1 Cubre-Colchón 30 reales & 1 Cubre-Colchón 10 reales & 1 Cubre-Colchón 10 reales \\
\hline 1 Colcha 50 reales & 1 Colcha 46 reales & 1 Colcha 45 reales \\
\hline 3 Sábanas 90 reales & 3 Sábanas 84 reales & 3 Sábanas 84 reales \\
\hline 4 Almohadas 24 reales & 4 Almohadas 36 reales & 4 Almohadas 36 reales \\
\hline 1 Cobertor 40 reales & & 1 Jergón 20 reales \\
\hline \multicolumn{3}{|l|}{1 Manta 30 reales } \\
\hline Total: 354 reales & Total: 236 reales & Total: 257 reales \\
\hline LECHO VII & LECHO VIII & \\
\hline Cuarto de las Criadas & Cuarto de las Criadas & \\
\hline 1 Cama 30 reales & 1 Cuja 8 reales & \\
\hline 1 Colgadura 450 reales & 1 Colchón 50 reales & \\
\hline 1 Colchón 50 reales & 1 Cubre-Colchón 10 reales & \\
\hline 1 Cubre-Colchón 30 reales & 1 Colcha 40 reales & \\
\hline 1 Colcha 100 reales & 3 Sábanas 84 reales & \\
\hline 3 Sábanas 132 reales & 4 Almohadas 20 reales & \\
\hline 4 Almohadas 32 reales & 1 Jergón 16 reales & \\
\hline \multicolumn{3}{|l|}{1 Cubre-Almohada 6 reales } \\
\hline \multicolumn{3}{|l|}{1 Manta 30 reales } \\
\hline Total: 860 reales & Total: 228 reales & \\
\hline \multicolumn{3}{|c|}{ Fuente Documental: AHPB. JM. Legajo 977 (1764), folios 21-127. } \\
\hline Elaboración propia. & & \\
\hline
\end{tabular}

de la viuda, dotado con una cama de 100 reales, una colgadura de 1.368 reales y múltiples menajes de revestimiento nocturno. A su lado, en misma estancia, otra cama, de 70 reales. En el «Quartto Siguiente al Estrado» se disponía un catre de 16 reales. En el «Quartto Siguiente, al Callejón», una cama de 34 reales. En el «Callejón, junto a la cozina», una cama vieja de 10 reales. En el «Quartto Siguiente o Despacho», un catre de 16 reales y en el «Quartto del Cochero», una cuja de 7 reales — Cuadro V-64.

64 Archivo Municipal de Burgos (AMB). Francisco Villafranca. Legajo HI-5253, 26 febrero de 1782, ff.1-71. 


\begin{tabular}{|c|c|c|}
\hline CUADRO IV/2 & \multicolumn{2}{|c|}{ Lechos nocturnos de Pedro Tomé González } \\
\hline & 1764 & \\
\hline \multicolumn{3}{|c|}{ Segunda vivienda: Contaduría Santa Cruzada } \\
\hline LECHO IX & LECHO X & LECHO XI \\
\hline Cuarto Principal & Cuarto Segundo & Cuarto Segundo \\
\hline 1 Cuja 8 reales & 1 Cama 120 reales & 1 Catre 30 reales \\
\hline 1 Colchón 50 reales & 1 Colgadura 150 reales & 1 Colchón 50 reales \\
\hline 1 Cubre-Colchón 10 reales & 2 Colchones 100 reales & 1 Cubre-Colchón 30 reales \\
\hline 1 Colcha 40 reales & 1 Cubre-Colchón 10 reales & 1 Colcha 50 reales \\
\hline 3 Sábanas 84 reales & 1 Colcha 96 reales & 3 Sábanas 84 reales \\
\hline 4 Almohadas 20 reales & 3 Sábanas 108 reales & 4 Almohadas 20 reales \\
\hline 1 Jergón 16 reales & 4 Almohadas 32 reales & 1 Cobertor 40 reales \\
\hline & 1 Manta 30 reales & 1 Manta 30 reales \\
\hline Total: 228 reales & Total: 646 reales & Total: 372 reales \\
\hline \multicolumn{3}{|c|}{ Fuente Documental: AHPB. JM. Legajo 977 (1764), folios 21-127 } \\
\hline Elaboración propia. & & \\
\hline
\end{tabular}

En resumen, el devenir de los lechos en los que yació Pedro Tomé a lo largo de sus matrimonios - CUADRO I - nos muestra un sostenido crecimiento tanto en número como en calidad, circunstancia sólo cercenada por su fallecimiento, si bien su viuda, anhelante de su presencia, también disfrutaba de lechos de notable consideración. Los comienzos fueron humildes. En 1703, dispusieron de dos camas completas, tasadas en 32 reales, dotadas de menajes nocturnos que sumaron 802 reales — no disponían de colgaduras - .

Contrastado con el promedio de la ciudad en esa fecha, el hogar de Pedro Tomé e Isabel de Castro estaba en sintonía con el panorama de la ciudad en su conjunto — CuAdro II—: 3 lechos, 36 1/2 reales en muebles, 496 1/2 reales en menajes nocturnos y 89 reales de las colgaduras — con un promedio de 619 reales/hogar- Fiel reflejo del progresivo enriquecimiento de Pedro Tomé en su primer matrimonio lo constituye la consideración de qué nos encontramos en 1724 en lo concerniente al descanso nocturno. Se había duplicado el número de lechos pero, sobre todo, y en esto el diagnóstico es irrefutable, se habían mejorado notablemente las calidades —el mobiliario ascendía a 440 reales_-, las disponibilidades en menajes — que en ese momento sumaban 2.779 reales - y se habían aclimatado en sus estancias íntimas las encubridoras colgaduras de las que anteriormente carecían — computadas en 1.376 reales_- Los lechos de Pedro Tomé en 1724 sumaban 4.595 reales — 5 1⁄2 veces más que al inicio del matrimonio en 1703 - Comparadas estas cifras con el promedio de la ciudad en 1724, el número de lechos era similar en cantidad y calidad — 185 reales_circunstancias extensivas a los menajes — 1.194 1/2 reales-, a las colgaduras —500 reales_, y al promedio global — 1.879 1/2 reales_- La calidad de vida y del descanso nocturno de Pedro Tomé e Isabel de Castro habían experimentado un crecimiento muy sobresaliente. 


\begin{tabular}{|c|c|c|}
\hline \multirow[t]{2}{*}{ CUADRO V } & \multicolumn{2}{|c|}{ Lechos nocturnos de Josefa Carrera Castro } \\
\hline & 1782 & \\
\hline LECHO I & LECHO II & LECHO III \\
\hline \multicolumn{3}{|l|}{ Lecho Cotidiano } \\
\hline Cuarto Principal & Cuarto Principal & Cuarto Siguiente Estrado \\
\hline 1 Cama 100 reales & 1 Cama 70 reales & 1 Catre 16 reales \\
\hline 1 Colgadura 1.368 reales & 3 Colchones 180 reales & 1 Cobertor 10 reales \\
\hline 3 Colchones 190 reales & 2 Sábanas 48 reales & 1 Lenzuelo 15 reales \\
\hline 2 Mantas 52 reales & 1 Cobertor 18 reales & 3 Almohadas 18 reales \\
\hline 2 Sábanas 48 reales & 2 Lenzuelos 16 reales & 4 Sábanas 120 reales \\
\hline 1 Cobertor 66 reales & 1 Colcha 60 reales & 1 Colcha 48 reales \\
\hline 2 Lenzuelos 28 reales & 1 Manta 80 reales & 1 Manta 32 reales \\
\hline 1 Colcha 90 reales & 4 Almohadas 16 reales & 1 Rodapie 3 reales \\
\hline 4 Almohadas 48 reales & 1 Rodapie 6 reales & \\
\hline \multicolumn{3}{|l|}{1 Cubre-Almohadas 4 reales } \\
\hline \multicolumn{3}{|l|}{3 Fundas 18 reales } \\
\hline Total: 2.012 reales & Total: 494 reales & Total: 262 reales \\
\hline LECHO IV & LECHO V & LECHO VI \\
\hline Cuarto Siguiente al Callejón & Cuarto Callejón junto Cocina & Cuarto Siguiente Despacho \\
\hline 1 Cama 34 reales & 1 Cama 10 reales & 1 Catre 16 reales \\
\hline 1 Colchón 44 reales & 1 Colchón 12 reales & 1 Colgadura 320 reales \\
\hline 1 Colcha 50 reales & 1 Lenzuelo 15 reales & 1 Colchón 44 reales \\
\hline 4 Sábanas 120 reales & 4 Sábanas 64 reales & 1 Colcha 200 reales \\
\hline 1 Lenzuelo 15 reales & 1 Colcha 44 reales & 1 Cobertor 16 reales \\
\hline \multirow[t]{5}{*}{4 Almohadas 16 reales } & 1 Jergón 20 reales & 1 Manta 18 reales \\
\hline & 4 Almohadas 16 reales & 1 Lenzuelo 15 reales \\
\hline & & 4 Sábanas 72 reales \\
\hline & & 1 Jergón 20 reales \\
\hline & & 4 Almohadas 15 reales \\
\hline Total: 279 reales & Total: 181 reales & Total: 736 reales \\
\hline \multicolumn{3}{|l|}{ LECHO VII } \\
\hline \multicolumn{3}{|l|}{ Cuarto del Cochero } \\
\hline \multicolumn{3}{|l|}{1 Cuja 7 reales } \\
\hline \multicolumn{3}{|l|}{2 Colchones 90 reales } \\
\hline \multicolumn{3}{|l|}{1 Pajero 10 reales } \\
\hline \multicolumn{3}{|l|}{2 Sábanas 24 reales } \\
\hline \multicolumn{3}{|l|}{1 Manta 10 reales } \\
\hline \multicolumn{3}{|l|}{1 Colcha 36 reales } \\
\hline \multicolumn{3}{|l|}{2 Almohadas 12 reales } \\
\hline \multicolumn{3}{|l|}{ Total: 189 reales } \\
\hline \multicolumn{3}{|c|}{ Fuente Documental: AMB. Legajo HI-5253 (1782), folios 1-71 } \\
\hline Elaboración propia. & & \\
\hline
\end{tabular}

Con la óptica de sus nupcias con Josefa Carrera (1725), y a tenor de lo alcanzado hasta el momento del fallecimiento de Pedro Tomé (1764), el devenir de su segundo matrimonio fue también espectacular — CUADRo I- A través de su inventario post-mortem, descubrimos la presencia en su hogar de 11 lechos — tasados en 410 reales_, de menajes nocturnos que prácticamente duplicaban lo habido en 1724 — con enseres tasados en 4.951 reales-, y colgaduras por valor de 1.700 reales. La suma total de lo dedicado a la cama era, en 1764, una cifra cercana a los 7.000 reales de vellón. Los promedios de la ciudad eran bastante más modestos —6 lechos, 88 1² reales en muebles, 1.688 
$1 / 2$ reales en menajes y 475 reales en colgaduras, es decir, un volumen total de 2.252 reales-. Su ausencia, tras el óbito, modificó, obviamente a la baja, los lechos nocturnos desplegados por Josefa Carrera, quien, en 1782, a la hora de su fallecimiento, disponía de 7 lechos, tasados en 253 reales, menajes nocturnos evaluados en 2.940 reales y varias colgaduras — cuya suma suponían 1.688 reales- L Las camas de Josefa Carrera fueron peritadas en 5.588 reales, es decir, prácticamente el doble de lo que, de promedio - Cuadro II-, disponían los hogares burgaleses de ese momento - 2.685 1/2 reales-. El número de camas y sus precios eran muy similares — 7 lechos, evaluados en 276 1/2 reales, pero los menajes (1.979 reales) y las colgaduras (430 reales) nos hablan de una mayor calidad en los despliegues nocturnos de Josefa Carrera respecto al promedio de las camas de la ciudad en su conjunto-.

Visto desde una perspectiva general, tanto para la ciudad en su conjunto como para las convivencias conyugales de Pedro Tomé en concreto - CuADRO VI-, el volumen de lechos, menajes y colgaduras nocturnas desplegadas para el descanso nocturno del empresario lanero eran cercanos, con las imprescindibles matizaciones puntuales, a los promedios hallados en los hogares de la nobleza rentista y los eclesiásticos más encumbrados. En sus inicios (1703), los enseres desplegados para el descanso nocturno estaban más en la línea del artesanado, de los tenderos o de los profesionales de los servicios públicos. Desde incluso antes de 1724-1725, sus magníficos negocios y estrategias de enriquecimiento le catapultaron hasta niveles de lo más acaudalado y exquisito de la ciudad, y sus camas, ya fueran en lo tocante a mobiliario, menajes o colgaduras, rivalizaban con lo más granado de Burgos, lejos, muy lejos, de los más paupérrimos — hilanderas y viudas, jornaleros, labradores y hortelanos, maestros y oficiales artesanos y tropas militares-y de los hogares de la mesocracia urbana — comerciantes al por mayor, burócratas, clérigos de baja y media extracción y militares de media o alta graduación—. La estancia diaria de Pedro Tomé en los brazos de Morfeo estuvo, durante gran parte de su existencia, imbricada entre los «príncipes» de la socioeconomía burgalesa, en lo que Ago denomina «Uno stilo di vita quasi-nobiliare»65. En una sociedad, la de la Edad Moderna, en que no todos podían permitirse el placer de la cama ${ }^{66}$, Tomé González dispuso, en todo momento, de un lecho para sus matrimonios y de camas para el resto de su progenie y servidumbre.

El devenir de algunos de los menajes que utilizaban en la vestimenta de sus lechos nocturnos (mantas, colchones, colchas y sábanas) ${ }^{67}$ — GRÁFIco III- ilus-

65 Renata Ago, Il gusto delle cose, págs. 75-81.

66 Raffaela SARTi, Vida en familia..., pág. 66.

67 Máximo García Fernández y Rosa Ma Dávila Corona, «Vestirse y vestir la casa. El consumo de productos textiles en Valladolid (1700-1860)», Obradoiro de Historia Moderna, 14 (2005), págs. 141-174) 


\begin{tabular}{|c|c|c|c|c|c|c|c|}
\hline \multirow[t]{2}{*}{ CUADRO VI } & \multicolumn{6}{|c|}{ Lechos nocturnos en el Burgos del Setecientos } & \\
\hline & & & & & & LECHO & \\
\hline CATEGORIAS SOCIO-PROFESIONALES & $\mathrm{N}^{\circ}$ LECHOS & MUEBLES & MENAJES & COLGADURAS & TOTAL & COTIDIANO & $\%$ \\
\hline HILANDERAS & 2 & 20 & 360 & 27 & 407 & 188 & 46.2 \\
\hline JORNALEROS & 2 & 21 & 289 & 4 & 314 & 169 & 53.8 \\
\hline LABRADORES+HORTELANOS & 3 & 32 & 481 & 23 & 536 & 171 & 31.9 \\
\hline ARTESANOS & 4 & 55 & 883 & 52 & 990 & 273 & 27.6 \\
\hline COMERCIANTES & 6 & 278 & 2.706 & 472 & 3.456 & 1.484 & 42.9 \\
\hline TENDEROS & 5 & 90 & 1.309 & 139 & 1.528 & 458 & 29.8 \\
\hline ESCRIBANOS N & 6 & 153 & 1.623 & 401 & 2.177 & 586 & 26.9 \\
\hline DERECHO (Procuradores y Abogados) & 7 & 258 & 1.593 & 1.149 & 3.000 & 791 & 26.4 \\
\hline ADMON_HACIENDA & 5 & 222 & 1.772 & 398 & 2.392 & 1.935 & 80.9 \\
\hline ADMON_ECLESIÁSTICAS & 6 & 200 & 1.879 & 572 & 2.651 & 718 & 27.1 \\
\hline SERVICIOS PÚBLICOS & 5 & 82 & 922 & 131 & 1.135 & 306 & 26.9 \\
\hline NOBLES RENTISTAS & 7 & 432 & 2.466 & 1.470 & 4.368 & 1.532 & 35.1 \\
\hline CLERO BAJO & 3 & 69 & 692 & 174 & 935 & 453 & 48.4 \\
\hline CLERO MEDIO & 3 & 68 & 718 & 223 & 1.009 & 546 & 54.1 \\
\hline CLERO ALTO (Canónigos) & 4 & 165 & 1.052 & 897 & 2.114 & 1.105 & 52.3 \\
\hline CLERO SUPERIOR (Dignidades) & 11 & 303 & 2.619 & 1.496 & 4.418 & 303 & 6.8 \\
\hline MILITARES: OFICIALES & 5 & 153 & 2.494 & 542 & 3.189 & 711 & 22.3 \\
\hline MLITARES: TROPAS & 4 & 17 & 444 & 0 & 461 & 165 & 35.8 \\
\hline TOTAL BURGOS & 4 & 128 & 1.172 & 352 & 1.652 & 482 & 29.2 \\
\hline PEDRO TOMÉ & 6 & 284 & 2.868 & 1.191 & 4.519 & 1.466 & 32.4 \\
\hline \multicolumn{7}{|c|}{ Fuente Documental: AHPB. PN y JM. Múltiples Legajos. } & \\
\hline
\end{tabular}

tra el grado de crecimiento en la importancia de las inversiones nocturnas en los hogares de Pedro Tomé. No sólo había más y mejores camas, en cantidad y calidad, más y mejores colgaduras —a modo de «estancias» en el interior de las estancias - sino que, además, se fueron dotando, a medida que incrementaban sus niveles de fortuna, con más y mejores menajes nocturnos. El dormir, aún en la intimidad silenciosa de los interiores domésticos, es también un relevante síntoma de la cultura de las apariencias y una proyección hacia los adentros del hogar de una historia social, la existencia de la familia en el seno del hogar.

\section{El «[H]echo cotidiano» en los hogares de Tomé González}

A lo largo de su existencia, y después de ella, Pedro Tomé ocupó un lugar imprescindible, ya fuera desde la óptica del descanso nocturno, ya fuera desde la perspectiva del ejercicio de la sexualidad, como espacio de enfermedad y/o convalecencia o, incluso, como mero, y nostálgico, recuerdo post-mortem, en, al menos, cuatro lechos. En ellos se alojó, nocturna o vespertinamente, en com-

y «El consumo de productos textiles en Valladolid, 1750-1850», Investigaciones Históricas, 21 (2001), págs. 133-179; Máximo García Fernández, «Visiones sobre el consumo textil popular de Antiguo Régimen en la Castilla interior», Estudis, 36 (2010), págs. 21-59 y «En casa y en la calle. Esposas y damas. Cultura material doméstica popular y apariencia a fines del Antiguo Régimen», en Ofelia Rey Castelao y Roberto LóPEz (eds.), El mundo urbano..., págs. 137-149. 


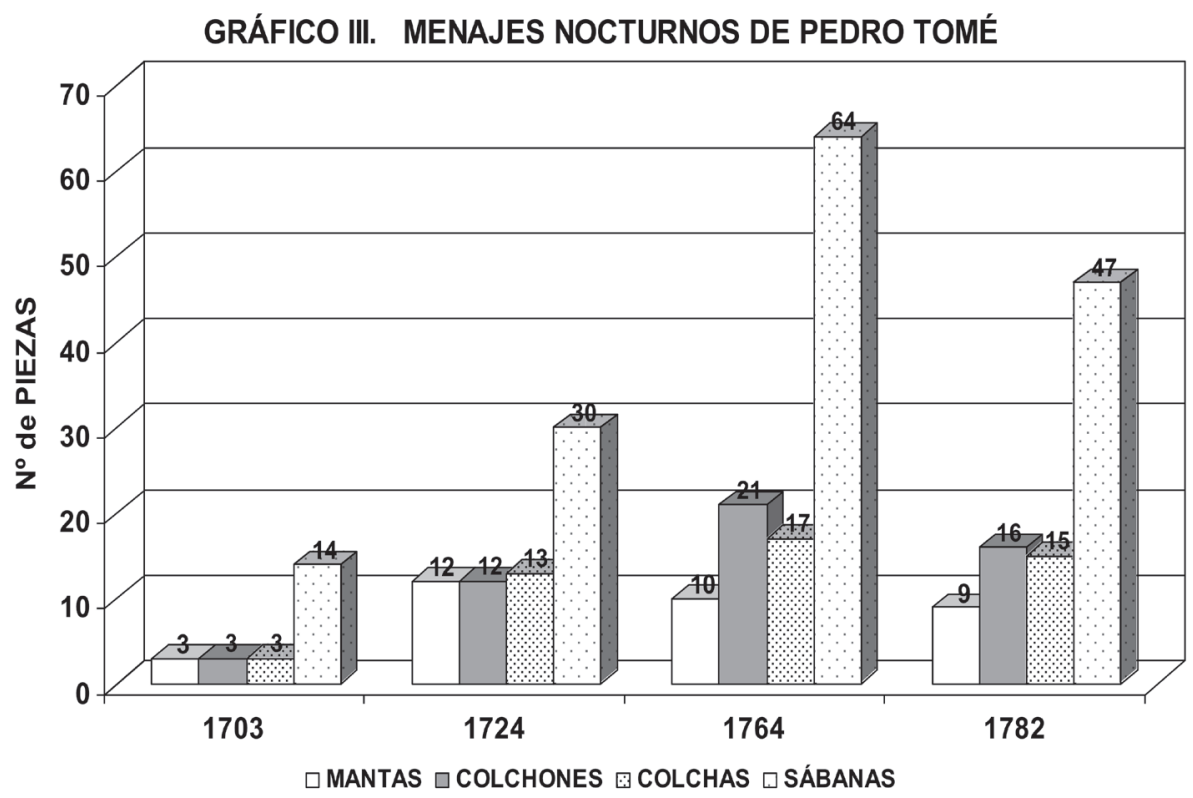

Elaboración propia. AHPB. PN. Múltiples Legajos.

pañía de dos mujeres, a las que arropó, que le arroparon, y con las que concibió descendencia. Auscultar las características de dichos cuatro lechos - su mobiliario, los menajes que sobre ellos se desplegaban y los cortinajes que les envolvía, a modo de «colgadura» para la intimidad y el resguardo— posibilita diagnosticar, en la medida de lo posible, algunos de los parámetros de su ubicación socioeconómica en el seno de la ciudad en la que residió, el Burgos del Setecientos —GRÁfico IV—.

En 1703, el lecho cotidiano de Pedro Tomé e Isabel de Castro sumaba, más o menos, 301 reales y estaba compuesto por una cama de haya (20 reales), un colchón (36 reales), un pajero (10 reales), dos lenzuelos (30 reales), tres sábanas (72 reales), una manta (16 reales), una colcha (55 reales), un cobertor (50 reales) y tres almohadas (12 reales) — CUADRo III_ ${ }^{68}$. El promedio de los lechos cotidianos en la ciudad de Burgos en ese año suponía, aproximadamente, 292 reales.

En 1724, el lecho cotidiano compartido conyugalmente, y testigo del fallecimiento de Isabel de Castro, ascendía a 1.537 reales, y estaba compuesto por una cama (400 reales), una colgadura (616 reales), dos colchones (160 reales),

68 AHPB. PN. José de Mata. Legajo 6917, 11 de enero de 1703, ff. 218-229. 
GRÁFICO IV. LECHOS NOCTURNOS DE PEDRO TOME

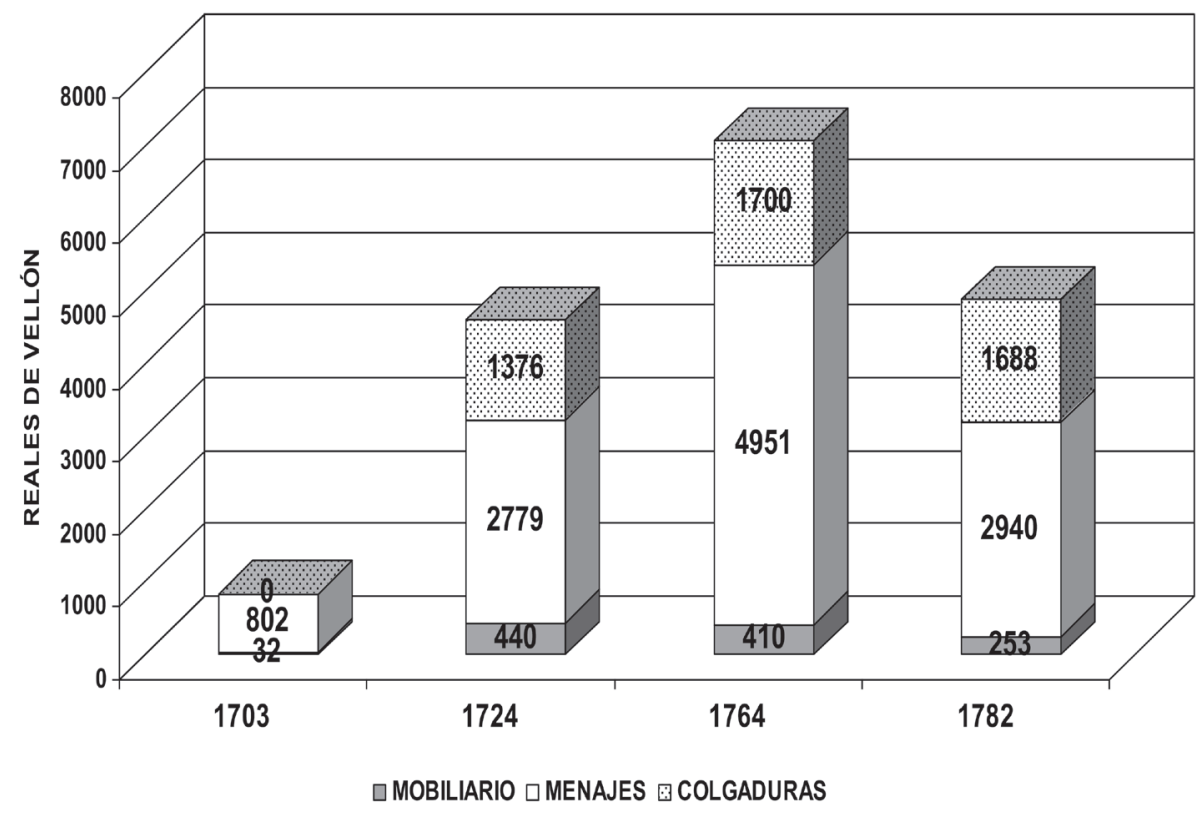

Elaboración propia. AHPB. PN. Múltiples Legajos.

un jergón (25 reales), dos lenzuelos (44 reales), cuatro sábanas (120 reales), dos mantas (40 reales), una colcha (120 reales) y cuatro almohadas (12 reales) Cuadro III—69. Los lechos cotidianos burgaleses de ese año se estiman en un promedio de 415 reales.

En 1764, Pedro Tomé abandonó la existencia en un lecho cotidiano evaluable en 2.014 reales de vellón, instalado en el «Quartto Primero Pral» de su residencia en la Plaza del Sarmental. Estaba compuesto por una cama (150 reales), una colgadura (1.000 reales), dos colchones (140 reales), un cubrecolchón (60 reales), tres sábanas (132 reales), una manta (90 reales), una colcha (350 reales), cuatro almohadas (20 reales), cuatro fundas (24 reales) y un cubre almohadas (20 reales) — CUADRo IV — ${ }^{70}$. El promedio de los lechos cotidianos en 1764 se estima en 386 reales de vellón.

En 1782, con la rotunda ausencia de Pedro Tomé desde 1764, Josefa Carrera se entregaba al descanso nocturno en un lecho cotidiano, sito en el «Quartto Principal» de la citada casa de la Plaza del Sarmental (5), evaluado en

${ }^{69}$ AHPB. PN. Martín Robredo. Legajo 6964, 14 de enero de 1724, ff. 340-353.

70 AHPB. JM. Juan Antonio Fernández Guilarte. Legajo 977, 14 de julio de 1764, ff. 21-127. 
2.012 reales. En él se desplegaban una cama (100 reales), una colgadura (1.368 reales), tres colchones (190 reales), dos lenzuelos (28 reales), dos sábanas (48 reales), dos mantas (52 reales), una colcha (90 reales), un cobertor (66 reales), cuatro almohadas (48 reales), tres fundas (18 reales) y un cubre almohadas (4 reales) — CuAdro V—⒈ En 1782, el promedio de los lechos cotidianos suponía, aproximadamente, 542 reales.

Pedro Tomé y Josefa Carrera «compartieron» la ciudad de Burgos con múltiples hogares a lo largo de gran parte del Setecientos, pendientes, en la cercanía o en la lejanía, más o menos, unos de otros. Ambos percibían lo que fueron en un principio, en la «prehistoria» de sus ocupaciones profesionales — con la tienda de joyería al fondo-; qué habían dejado al paso — al implicarse, de manera creciente, en los quehaceres de la burocracia de las Administraciones Eclesiásticas — sea como mayordomo del Cabildo Catedral o gestores de las responsabilidades de la Santa Cruzada o del papel sellado- y cuáles eran sus apetencias, aunque fueran utópicas, puestos sus ojos en las estancias nocturnas y en la cultura de las apariencias de aristócratas de notable raigambre - CuADRO VII-.

Juan Hermosilla (1732) ejemplifica el paradigma de sus humildes orígenes, el de un modesto mercader de joyería, cuyo inventario post-mortem sumó, al hilo de su óbito, poco más de 3.500 reales de vellón. Su «hecho Cotidiano», computado en 182 reales, nos retrotrae a los momentos más oscuros y desconocidos, de menor lustre y más débil economía en la existencia burgalesa de Pedro Tomé ${ }^{72}$. En un segundo término, el «Lecho cotidiano» de don Fernando Aguado Invicto de Robles (1785), tesorero del Hospital del Rey, valorado en 1.041 reales, materializa la etapa intermedia en que, abandonado el «mundillo» comercial, se adentraron en las singladuras de los quehaceres burocráticos y el negocio lanar. El inventario post-mortem del susodicho Fernando alcanzaba casi los 110.000 reales $^{73}$. En última instancia, don Gonzalo de Hoces y Córdoba (1738), poseedor del lecho cotidiano mejor dotado de entre los recopilados para el Burgos del XVIII, con 5.894 reales en mobiliario, menajes y colgaduras — instalado todo ello en el «Cuarto Dormitorio de Verano» — CuAdro VII—, sería uno de los modelos a emular para el diseño de los lechos nocturnos de la ciudad. Los bienes libres tasados en su inventario post-mortem — poco más allá de los 50.000 rea$\operatorname{les}^{74}$ —en nada competían con el millón y medio largo de Pedro Tomé en $1764^{75}$.

\footnotetext{
71 AMB. Francisco Villafranca. Legajo HI-5253, 26 de febrero de 1782, ff. 1-71.

72 AHPB. PN. Martín Robredo. Legajo 6972, 15 de julio de 1732, f. 430 (423-432).

73 AHPB. PN. Andrés Martín García. Legajo 8319, 19 de enero de 1785, f. 57 (25-72).

74 AHPB. PN. Jacinto del Río. Legajo 7051/2, 24 de octubre de 1738, ff. 221-222 (221-245).

75 AHPB. JM. Juan Antonio Fernández Guilarte. Legajo 977, 14 de julio de 1764, ff. 21-127.
} 


\begin{tabular}{|c|c|}
\hline CUADRO VII & Cuatro modelos de lecho nocturno \\
\hline 1732 & 1785 \\
\hline Juan Hermosilla & Fernando Aguado Invicto Robles \\
\hline 1 Cama de haya 12 reales & 1 Cama imperial de pino 200 reales \\
\hline 1 Jergón de estopa 10 reales & 1 Colgadura de damasco 300 reales \\
\hline 3 Colchones de estopa 99 reales & 1 Rodapie de damasco 15 reales \\
\hline 1 Lenzuelo de estopa 18 reales & 2 Mantas de Palencia 66 reales \\
\hline 1 Sábana de lienzo casero 14 reales & 4 Colchones de lona y terliz 320 reales \\
\hline 1 Manta de blanqueta 14 reales & 4 Sábanas de true y crea 100 reales \\
\hline 1 Cobertor 10 reales & 4 Almohadas de true 20 reales \\
\hline 2 Almohadas con lana 5 reales & 4 Fundas de mitan 28 reales \\
\hline & 1 Cubre-Almohadas de lienzo 12 reales \\
\hline Total: 182 reales & Total: 1.041 reales \\
\hline 1738 & 1764 \\
\hline Gonzalo de Hoces y Córdoba & Pedro Tomé González \\
\hline 1 Armadura de Cama de Baldusal 1.000 reales & 1 Cama de nogal150 reales \\
\hline 1 Colgadura de damasco carmesí 4.500 reales & 1 Colgadura de tafetán 1.000 reales \\
\hline 2 Colchones de terliz 160 reales & 2 Colchones de terliz 140 reales \\
\hline 2 Sábanas de holanda 120 reales & 2 Cubre-Colchones de terliz 60 reales \\
\hline 2 Mantas de Palencia 36 reales & 1 Colcha de lana 350 reales \\
\hline 4 Almohadas de holanda con fundas 34 reales & 3 Sábanas de lienzo 132 reales \\
\hline \multirow[t]{4}{*}{1 Almohadón con su lana 20 reales } & 4 Almohadas de holanda 48 reales \\
\hline & 1 Cubre-Almohadas de tafetán 20 reales \\
\hline & 4 Fundas de terliz 24 reales \\
\hline & 1 Manta de lana 90 reales \\
\hline Total: 5.894 reales & Total: 2.014 reales \\
\hline \multicolumn{2}{|c|}{ Fuentes documentales: Véanse referencias de archivo en el texto y notas } \\
\hline Elaboración propia. & \\
\hline
\end{tabular}

Las cantidades invertidas en los lechos nocturnos, y en especial en el «Hecho Cotidiano», les colocaban en «mundos» antagónicos y diametralmente diferentes. Y las calidades también. Hermosilla durmiendo sobre la vulgar madera de haya y envuelto en estopa, lienzo casero, blanqueta y lana — tejidos baratos y bastos-. Fernando Aguado reposaba en su rutilante cama imperial de pino, rodeado, en la nocturnidad, de damasco, terliz, trae, mitán y lienzo. Gonzalo de Hoces se regodeaba en su cama de Baldusal, envuelto en damasco, terliz y holanda - tejidos característicos de un diagnóstico de confortabilidad, boato y lujo-. A la postre, Pedro Tomé yacía sobre la elitista madera de nogal. Sus cuerpos se envolvían, en la noche, en tafetán, terliz, lienzo, holanda y lana — géneros más modestos que los de la aristocracia pero lejanos de la nausea hedionda de lo paupérrimo y aclimatados a la esencia de un parveni que escaló, progresiva pero rápidamente, desde la humildad de una tienda de joyería y especiería hasta la cima de los más acaudalados próceres de Burgos en el Setecientos-. 


\section{Conclusiones}

La historia social se zambulle, en esta ocasión, en lo nocturno. La reconstrucción de los lechos utilizados en los hogares encabezados por Pedro Tomé González posibilita, en contraste con los regentados por los restantes vecinos de Burgos a lo largo del siglo XVIII, efectuar un análisis crítico de sus características y peculiaridades y sondear cómo fueron incrementando sus dotaciones, cantidades y calidades. A medida que incrementaba su nivel de fortuna y su nivel de rentas, con la asunción de nuevos quehaceres y riesgos empresariales, el descanso nocturno en casa de los Tomé fue cada vez más eficiente y lujoso. La problemática de fondo era escapar, en la medida de lo posible, de sus iguales en los momentos más turbios y humildes, para, después, ir escalando, en virtuosismo y confortabilidad. Se tendía hacia un «hecho cotidiano» del matrimonio, y de los restantes lechos nocturnos del hogar, con mejores y mayores cantidades de menajes y de colgaduras y hacia los más selectos en tejidos y durabilidad, a medida que se ascendía en el escalafón socioeconómico.

Es, lo sabemos, un caso aislado, merced a la disponibilidad de varios inventarios de bienes engranados en el devenir del Setecientos. Empero, se perfila como un modelo de reconstrucción histórica paradigmática, con una óptica poliédrica y en tres dimensiones. Es una herramienta de micro-historia que tiene sabor a historia social, historia de la cultura material e, incluso, historia de las emociones. Los objetos y los sujetos adquieren protagonismo como integrantes de procesos culturales y la creación de significados entendidos como el resultado de sus interacciones. Constituyen dinámicas relacionadas con la variabilidad de las personas y los objetos, dentro de la estructura social en la que se encuentran inmersos. La «humildad de las cosas» —en este caso de los lechos nocturnos - permite, a pesar de todo, calibrar sus comportamientos, sus estrategias y sus emociones ${ }^{76}$.

«Il gusto delle cose» se despliega por la totalidad del atrezzo de los interiores domésticos, siempre acorde a las capacidades de consumo y de los niveles de fortuna. La disposición de los lechos nocturnos no era en el Setecientos, ni lo es en la actualidad, un mero discurso neutro. La colocación y confortabilidad de las camas, de los menajes y de las colgaduras acogía las horas de descanso nocturno, imprescindibles para el desarrollo de los múltiples quehaceres sociales y profesionales de los períodos vespertinos. Dormir confortablemente alimenta el dinamismo en la vigilia.

76 Juan Manuel Zaragoza Bernal, «Ampliar el marco. Hacia una historia material de las emociones», Vínculos de Historia, 4 (2015), págs. 28-40. 
El despliegue de pertrechos y enseres en el seno de los interiores domésticos nos adentra en las dinámicas de los niveles de consumo en la España Moderna. Las trayectorias sociales, económicas y profesionales de los hogares acababan fraguando, y materializándose en la práctica, en su capacidad para pertrecharse, en suma, de bienes que resumen sus condiciones de vida, y viceversa. Ya fuera en la compra directa en el mercado o a través de las almonedas, para dotarse de artículos de segunda mano ${ }^{77}$, los hogares conformados por Pedro Tomé disfrutaron de mobiliarios, menajes y colgaduras para acogerse en la nocturnidad. Todo era comprado, vendido, aclimatado o desechado, en una estrategia consciente y deliberada, de adecuarse, en la medida de lo posible, a un estilo de vida, fuera éste burgués, artesano, nobiliar o paupérrimo ${ }^{78}$.

77 Entre otras, las propuestas de Juan Manuel Bartolomé Bartolomé, «El comercio de oportunidades en la provincia de León: las almonedas urbanas y rurales (1700-1850)», Tiempos Modernos, 22 (2011), págs. 1-19 y Máximo García Fernández, «Cultura material, consumo, moda e identidades sociales: la almoneda de bienes», Máximo García Fernández (dir.), Cultura material y vida cotidiana moderna: Escenarios, Madrid, Sílex, 2013, págs. 235-259.

78 Resultan de imprescindible consulta Ramón Maruri Villanueva, «La historia social del consumo en la España moderna: un estado de la cuestión», Estudis, Revista de Historia Moderna, 42 (2016), págs. 267301; Enrique Llopis Agelán, El legado del Antiguo Régimen en España, Barcelona, Crítica, 2004; Enrique Llopis, Jaume Torras y Bartolomé Yun (eds.), El consumo en la España pre-industrial, Revista de Historia Económica, n. ${ }^{\circ}$ extraordinario (2003), Juan Manuel Bartolomé BaRtoloné, «Los comportamientos sociales ante el consumo en España en la edad moderna: la llegada de novedades en los espacios domésticos en la provincia de León (1700-1850)», Itinerari di recerca storica, 1 (2017), págs. 151-166; Juan Manuel BarTolomé BaRTolomé y Máximo García Fernández (Dirs.), Apariencias contrastadas: Contraste de apariencias. Cultura material y consumo de Antiguo Régimen, León, Universidad de León, 2012; Daniel Muñoz Navarro (ed.), Comprar, vender y consumir. Nuevas aportaciones a la historia del consumo en la Edad Moderna, Sevilla, Universidad de Valencia, 2011 y, por supuesto, Neil McKendrick, John Brewer y J. H. Plumb, The Birth of a Consumer Society. The Commercialization of Eighteenth-Century England, Londres, Indiana University Press, 1982. 